1

2

3

\title{
The influence of expansion rates on mandibular distraction osteogenesis: a computational analysis
}

\author{
A. Boccaccio ${ }^{1,2}$, C. Pappalettere ${ }^{1}$, D.J. Kelly ${ }^{2 *}$ \\ ${ }^{I}$ Dipartimento di Ingegneria Meccanica e Gestionale, Politecnico di Bari, 70126, Bari, Italy \\ ${ }^{2}$ Centre for Bioengineering, Department of Mechanical and Manufacturing Engineering, Trinity College Dublin, Ireland.
}

*Corresponding author:

Dr. Daniel Kelly

Mailing Address:

Centre for Bioengineering,

Department of Mechanical Engineering,

Trinity College Dublin,

Dublin 2,

Ireland.

Contact Information:

Tel: +353-1-6083947 (Daniel Kelly);

Fax: +353-1-6795554 (Daniel Kelly);

Email: kellyd9@tcd.ie (Daniel Kelly);

Keywords: Mechanobiology; Mandibular distraction osteogenesis; Osteotomized human mandible; Tissue differentiation; Finite element analysis. 
Mandibular distraction osteogenesis is a clinical procedure used for modifying the mandibular geometry when problems of dental overcrowding and arch shrinkage occur. The objective of this study is to use a computational model of tissue differentiation to examine the influence of the rate of distraction on bone regrowth within the fracture callus of a human mandible submitted to symphyseal distraction osteogenesis. A 3D model of the mandible is reconstructed from CT scan data and meshed into finite elements. Two different mastication loadings have been investigated: a 'full' mastication load and a 'reduced' mastication load where the action of each muscle was reduced by $70 \%$. Four different distraction rates were analysed: $0.6 \mathrm{~mm} / \mathrm{day}, 1.2$ $\mathrm{mm} /$ day, $2 \mathrm{~mm} /$ day and $3 \mathrm{~mm} /$ day, allowing a total displacement of $6 \mathrm{~mm}$. In the early stages of the distraction process it is predicted that there is a decrease in the amount of bone tissue forming within the centre of the fracture gap for all distraction rates. After the initial phases of expansion, the bone tissue within the callus increases for the slower rate of distraction or continues to decrease at the faster rates of distraction. At the end of the simulated maturation period, $47 \%$ of the distracted callus was predicted to consist of bone tissue for a distraction rate of $0.6 \mathrm{~mm} /$ day, decreasing to $22 \%$ for a distraction rate of $3 \mathrm{~mm} /$ day. Significantly higher amounts of bone formation were predicted for all distraction rates for the case of reduced mastication loading. Disparities between the model predictions and what is observed in vivo were found. For instance, during the latency period, the distraction period and beyond, the model is predicting larger than expected amounts of cartilage tissue formation within the callus. This and other limitations of the proposed model are discussed and possible specific explanations for these disparities are provided in the paper. The model predicts a distraction rate of around $1.2 \mathrm{~mm} /$ day to be optimal as higher rates produce less bone tissue while the risk of a premature bone union is greater at slower rates of distraction because in the latter stages of the distraction process bone tissue is predicted to form between the left and right side of the bone callus. 


\section{Introduction}

The use of distraction osteogenesis for correcting problems of posterior buccal unilateral occlusion and mandibular anterior crowding, as a common clinical practice, dates from the 1990s after several successful studies on humans and animals. ${ }^{14,16,17,42}$ With Mandibular Symphyseal Distraction Osteogenesis (MSDOG) the mandibular shape is modified definitively and more space is created on the inferior arch so that the teeth, which are initially in intimate contact, can be repositioned in the correct locations. Clinically, MSDOG can be divided into four stages: firstly the mandible is osteotomized and then instrumented with a distraction appliance; secondly a seven to ten day latency period is provided after the surgical operation in order to allow the formation of a good quality bone callus; thirdly the distraction device is progressively expanded with a well defined rate for seven-ten day time period; the final stage is the maturation period during which the patient is maintained in rigid external fixation. The third stage is crucial for successful MSDOG. Too fast a rate of expansion of the appliance can lead to poor bone quality within the distraction gap, partial union, fibrous union or atrophic non-union. Conversely, too slow a rate can lead to premature consolidation hence hindering the distraction process. ${ }^{10}$ Ideally a continuous form of distraction is applied, however this is clinically impractical and most reports have used distraction frequencies of 1-2 times daily. ${ }^{11,14}$

Various studies have investigated the mechanisms of bone formation during distraction of the mandible, however different treatment protocols etc among various authors have made direct comparison of the effects of the applied biophysical stimuli on distraction osteogenesis almost impossible ${ }^{32}$. Using a rat model, Paccione et $a l .{ }^{34}$ demonstrated that both the rate and the frequency (or rhythm) of distraction influences the adaptive response within the fracture callus. The rate of distraction was observed to have a greater effect than the frequency. Meyer et al. ${ }^{30}$ demonstrated in a rabbit model of mandibular distraction osteogenesis that cell differentiation, apoptosis and tissue development in the callus were related to applied strain magnitudes. Loboa et al. ${ }^{26,27}$ carried out a broad study on the mechanobiology of the distraction osteogenesis by using a rat model submitted to hemimandibular osteotomy. They compared histological findings with the strain and pressure fields 
determined using a finite element model and observed that tensile strains up to $13 \%$ corresponded to regions of new bone formation and regions of periosteal hydrostatic pressure with magnitudes less than $17 \mathrm{KPa}$ corresponded to locations of cartilage formation. They also concluded that higher strain values are localized in the center of the distraction gap, and that tissue damage would occur if the tissue was not compliant enough to resist such high strains. The finite element method has also been used by a number of other authors to analyze mandibular distraction osteogenesis. Boccaccio et al. $^{5}$ used the finite element method to investigate the mechanical behaviour of an osteotomized mandible with a tooth-borne distraction device. They compared two different expansion protocols: the first one in which the device is expanded by $0.6 \mathrm{~mm} /$ day and the second one where the expansion given to the device is $1.2 \mathrm{~mm} /$ day. They concluded that higher rates of expansion reduce the stress in the mandible and allow better control of the displacement field induced on the mandibular arch. The same authors ${ }^{6}$ have also investigated how the displacement and stress field induced by the device in the mandible changes when full mastication loads are applied. An average change of $7 \%$ in the displacement field was predicted, with a maximum Von Mises stress of about $30 \mathrm{MPa}$ in regions close to the point where the device is attached to the mandible. Using a finite element model of a human mandible submitted to midline distraction osteogenesis, Basciftci et al. ${ }^{4}$ found that high stress levels are localized in the ramal region. Despite these studies, our understanding of the mechanobiology of distraction osteogenesis is still incomplete, and to the knowledge of the present authors, no studies are reported in the literature providing a mechano-biological explanation for the influence of the distraction rate on mandibular distraction osteogenesis.

Different models have been proposed which relate tissue differentiation to the mechanical environment within the mesenchymal tissue. ${ }^{8,9,15,35,36}$ Prendergast et al. $^{36}$ proposed a mechanoregulation model where the bone callus is assumed to be a poroelastic material and the stimulus regulating tissue differentiation is hypothesized to be a function of tissue shear strain and the interstitial fluid flow. This model was used to successfully predict the patterns of tissue differentiation during fracture healing ${ }^{25}$, at implant/bone interfaces ${ }^{2,19}$ and during osteochondral defect repair. ${ }^{23}$ In 
this study, this same model will be further developed in order to investigate mandibular distraction osteogenesis, and in particular, to perform a computational mechanobiological analysis on the rate of expansion of the device. Four different protocols of expansion will be investigated: the first one where the device is distracted by $0.6 \mathrm{~mm} /$ day for a period of ten days, the second where the device is distracted at $1.2 \mathrm{~mm} /$ day for five days, the third where the device is distracted by $2 \mathrm{~mm} /$ day for three days and the fourth where the device is distracted by $3 \mathrm{~mm} /$ day for two days. The final result with the aforementioned protocols is a widening of mandibular arch by about $6 \mathrm{~mm}$ corresponding to the space occupied by a lower incisor. The spatial and temporal changes in tissue differentiation produced with these different protocols will be compared. Furthermore, the influence of the mastication forces on the patterns of tissue differentiation within the callus will be investigated.

\section{Materials and methods}

\subsection{The mechano-regulation algorithm}

Spontaneous repair begins immediately after osteotomy. Mesenchymal stem cells (MSCs) invade the fracture callus from the adjacent bone marrow and begin to proliferate and differentiate. The spreading of cells throughout the callus was described by the following diffusion equation:

$$
\frac{\mathrm{d} c}{\mathrm{~d} t}=D \nabla^{2} c
$$

where $c$ denotes the concentration of cells in a given volume and $D$ is the diffusion coefficient. The parameters of Eqn. 1 (i.e. the $D$ diffusion coefficient) were set so that complete cell coverage in the callus is achieved two weeks after the osteotomy (assuming no distractions were performed). The same value for the diffusion coefficient was chosen for each distraction rate (Note: Allowing MSCs to also migrate from the surrounding soft tissue, i.e. including a second source of MSCs, did not significantly effect the predictions of the model). As cells disperse throughout the repair tissue, they 
are hypothesized to differentiate depending on the magnitude of a biophysical stimulus. Following previous work $^{19,23,25,36}$, the biophysical stimulus for tissue differentiation is taken to be a function of the octahedral shear strain $\gamma$ and interstitial fluid flow $v$ in the extracellular environment of the cells according to:

$$
S=\frac{\gamma}{a}+\frac{v}{b}
$$

$a$ and $b$ being empirical constants, where $a=3.75 \%$ and $b=3 \mu \mathrm{ms}^{-1} .{ }^{19}$

Cells can differentiate into the following cell phenotypes and synthesise a new tissue type based on the value of $S$ :

$$
\text { if }\left\{\begin{array}{l}
S>m \Rightarrow \text { fibroblast }: \quad \text { fibrous connective tissue } \\
1<S<m \Rightarrow \text { chondrocyte: cartilage } \\
n_{\text {mature }}<S<1 \Rightarrow \text { osteoblast: immature woven bone } \\
n_{\text {resorbtion }}<S<n_{\text {mature }} \Rightarrow \text { osteoblast: mature woven bone } \\
0<S<n_{\text {resorbtion }} \Rightarrow \text { osteoclast: bone resorbtion }
\end{array}\right.
$$

where $n_{\text {resorbtion, }} n_{\text {mature }}$ and $m$ represent boundaries of the mechano-regulation diagram for tissue differentiation. Their values were taken to be the same as those utilized by Lacroix and Prendergast ${ }^{25}$ in a simulation of fracture healing $\left(n_{\text {resorb }}=0.01, n_{\text {mature }}=0.53, m=3\right)$.

As cells differentiate and synthesise new matrix, the mechanical properties of the callus will change. The temporal change in $E_{i}$, the Young's Modulus for tissue phenotype $i$ (where $i$ is fibrous tissue, cartilage or immature or mature bone), was described using the following equation:

$$
E_{i}=K_{i} e^{\gamma_{i} \cdot t}
$$


where $t$ is the time since the osteotomy and $K_{i}$ and $\gamma_{i}$ are two parameters regulating the shape of the exponential curve. The choice of an exponential increase in Young's modulus $E$ with time was made based on the results of Richardson et al. ${ }^{37}$ who observed an exponential increase in callus stiffness during tibial fracture healing. The values of $K_{i}$ and $\gamma_{i}$ have been set so that the Young's Modulus of tissue phenotype $i$ increases in 75 days from the initial value of $0.2 \mathrm{MPa}$, typical of granulation tissue, to the values utilized in previous studies ${ }^{23,25}\left(E_{\text {fibrous }}=2 \mathrm{MPa} ; E_{\text {cartilage }}=10 \mathrm{MPa} ; E_{\text {immature bone }}=1000\right.$ $\mathrm{MPa} ; E_{\text {mature bone }}=6000 \mathrm{MPa}$ ). Table 1 illustrates the values of $K_{i}$ and $\gamma_{i}$ used in the algorithm. The time period of 75 days was chosen based on an average of times reported in the literature for the consolidation and the calcification of the fracture callus. ${ }^{10,20}$ The same time scale was set for the maturation of fibrous and cartilaginous tissue.

The calculation of $E$ for every element of the model and for every iteration was made based on the exponential law (Eqn. 4) and a simple rule of mixtures. If $\bar{E}$ is the average Young's Modulus for a given element for the ten previous iterations and if $c$ is the concentration of cells invading the domain in the iteration iter evaluated with Eqn. 1, then the Young's modulus for that element and for next iteration iter +1 will be given by:

$$
E(\text { iter }+1)=\frac{c}{c_{\max }} \cdot \bar{E}+\frac{\left(c_{\max }-c\right)}{c_{\max }} \cdot E_{\text {granulation }}
$$

and

$$
\bar{E}=\frac{1}{10} \sum_{i t r=p}^{p+10} E_{i}(\text { iter })
$$

where $c_{\max }$ is the maximum concentration of cells which may occupy any one element domain, $E_{\text {granulation }}$ is the Young's Modulus of the granulation tissue and $p$ is the tenth last iteration. Regarding 
the other mechanical properties (e.g. bulk solid modulus, permeability etc.), as scant information is available on their evolution in time during the tissue differentiation process, it was assumed that these material properties changed based only on the rule of mixtures as used in other studies ${ }^{23,25}$.

\subsection{Finite element model}

CT scan data was used to build a 3D finite element (FE) model of the human mandible (Fig. 1b). (A photoelastic model of which is shown in Fig. 1a). The CT data were processed by means of the Mimics ${ }^{\circledR}$ Version 7.2 software (Materialise Inc). In particular, the built-in MedCAD ${ }^{\circledR}$ module in Mimics $^{\circledR}$ was used in order to generate NURBS (Non Uniform Rational B-Splines) surfaces delimiting the morphology of the virtual model. The anatomy of the mandibular arch was then imported in the software $F E M A P^{\circledR}$ where the finite element mesh was generated. A tooth-borne device was added to the mandibular geometry. The appliance consists of one band on the first mandibular molar, and one band on the first mandibular premolar, on both sides of the arch. Bands are steel rings connected by a $1.1 \mathrm{~mm}$ diameter stainless steel $(E=210000 \mathrm{MPa}, v=0.3)$ wire and a screw positioned behind the lower incisors (Fig. 1a). Considering that the stiffness of the mandibular bone is much greater than that of the callus, the portions of the mandible and of the device far from the distraction gap have been modelled as 3D rigid surfaces (element R3D3, ABAQUS $6.4{ }^{45}$ ). Conversely, the portion of the bone, the callus and of the device near to the middle sagittal plane were modelled with 3D deformable eight noded elements. With this strategy, the computational cost of the finite element model (FEM) simulations is significantly reduced without introducing, within the computational model, significant alterations with respect to the anatomo-physiological behaviour of the mandibular district. (A preliminary numerical test has been carried out in order to test the validity of such an assumption. Simplified prismatic models of the bone-callus-bone structure shown in Fig. $1 \mathrm{~b}$ were built and the lengths of the portion of model representing the bone (both cortical and cancellous) were progressively increased. The models were then submitted to loading conditions similar to that acting on the bone callus during the distraction process. The sensitivity of the strain and 
the pore fluid velocities to the length of the bone was investigated. This analysis shows that the influence of the length of bone on the results obtained is negligible.) About 12000 3-node undeformable triangular elements compose the irregular and complex surfaces of the model far from the middle sagittal plane and 5432 8-node hexahedral elements compose the osteotomized region and the deformable portion of the distractor (Fig. 1b). Following Meyer et al. ${ }^{31}$, a $2 \mathrm{~mm}$ thick fracture gap between the two mandibular ramus was created (Fig. 1f). The callus was meshed using eight layers of elements $0.25 \mathrm{~mm}$ thick, while elements $0.5 \mathrm{~mm}$ thick were used to mesh the bone tissue on both the right and the left side of the callus (Fig. 1d, Fig. 1e). The callus is surrounded by cortical and cancellous bone (Fig. 1d, Fig. 1e). The elements that make up the model of surrounding bone tissue were attached to the rigid part of the model by tying the nodes of the deformable region with those of the other. The same strategy was used to bond the deformable portion of the device with the rigid one. The number and the type of elements used in the model are listed in Table 2.

The FEM model was subjected to four boundary conditions (see Fig. 2). Boundary condition (i) simulates the temporomandibular joint (Fig. 2b). Two reference points placed at the locations of articulation represent the condyles. Coupling constraints connect the reference points to the mandible arms. The temporomandibular joint disc was simulated by constraining these reference points to three fixed points by means of spring elements aligned to the coordinate system. In this way, the mandible can rotate about an axis defined by the line connecting the two condyles and translate along the coordinate directions. Boundary condition (ii) models the mastication phase (Fig. 2a). The action of the most important muscles involved in the mastication process, the masseters, the temporals and the pterygoid muscles, are included. Loads are applied at points where muscles are inserted into the mandibular bone. Two different mastication loads have been applied on the model. A full mastication load where the values of forces of each muscle are the same as those used in a previous work ${ }^{5}$ and evaluated by Faulkner et al. ${ }^{13}$; and secondly a reduced mastication load where the force developed by each muscle was reduced by $70 \%$. Boundary condition (iii) simulates the unilateral occlusion on one tooth on the right (with respect to the observer) mandibular arm (see details in Fig. 2e). The action of 
chewing on the mandibular arch is modelled by constraining, with simple-supports preventing $u_{3}$ displacements, the second premolar. Typically the mastication process occurs on one side of the mandibular arch, however in the initial stages of mastication it is reasonable to assume that the occlusion occurs on one tooth in particular. Boundary condition (iv) simulates the process of expansion of the distractor (Fig. 2d). Further details of the finite element model and the applied boundary conditions are available elsewhere ${ }^{5}$.

The bone callus and adjacent bone tissue were modelled as poroelastic materials. The cortical bone was modelled as an orthotropic material $\left(\mathrm{E}_{11}=20000 \mathrm{MPa}, \mathrm{E}_{22}=12000 \mathrm{MPa}, \mathrm{E}_{33}=14000 \mathrm{MPa}\right.$; $v_{12}=0.36, v_{13}=0.33, v_{23}=0.2$ ), the principal material directions and elastic moduli of which have been taken from Schwartz-Dabney and Dechow. ${ }^{39}$ The material properties used for all other tissues are listed in Table 3 while the principal material directions $(1,2,3)$ are shown in Fig. 1d.

\subsection{Implementation of mechano-regulation model to simulate distraction osteogenesis}

Eqn. 1 was solved using a mass diffusion element in Abaqus. ${ }^{45}$ Each iteration corresponds to 4.8 hours. The total number of iterations was set in order to cover a time period of 43 days, consisting of a one week latency period and a 37 day distraction and maturation period. In the case of the $0.6 \mathrm{~mm} /$ day distraction rate, this latter period included ten days of distraction and a 27 day maturation period, while the $1.2 \mathrm{~mm} /$ day distraction rate consisted of five days of distraction and a 32 day maturation period. In the case of the $2 \mathrm{~mm} /$ day and $3 \mathrm{~mm}$ /day distraction rates, three and two expansion processes are simulated with a 34 and 35 day maturation period respectively. The choice of a one week latency period was made according to the suggestion of Conley and Legan. ${ }^{10}$ The equations describing cell dispersal and differentiation, and the subsequent change in the mechanical properties of the differentiating tissues, were implemented into an algorithm, a graphical summary of which is depicted in Fig. 3. In the case of iterations in which no distraction processes will be simulated, (Block 3), the mastication loads (Block 4) were applied on the mandibular model and a FEM analysis was run (Block 5) in order to evaluate, according to Eqn. 2, the biophysical stimulus $S$ (Block 6). Based on the 
computed value of $S$, the new tissue phenotype for every element in the callus was calculated (Block 7 and Block 8). The diffusion analysis (Block 9) is then solved, and based on the exponential law (Eqn. 4) (Block 10) and the rule of mixtures (Eqn. 5) (Block 11) the mechanical properties of every element to be used in the next iteration of the model were calculated.

In the case of iterations which simulate a distraction process (Block 3), a preliminary structural FE analysis was run in order to model just the expansion of the appliance (Block 15). In this analysis the portion of the device next to the middle sagittal plane simulating the screw for opening the gap was removed (Fig. 2c-d) and a given displacement (along direction 1, see Fig. 1b) was imposed to the two free arms of the distractor over a time period of 120 seconds. No mastication loads were applied, i.e. it is assumed that during the distraction process the patient does not chew. Again, the biophysical stimulus $S$ (Block 16) and the new tissue phenotype are evaluated for every element (Block 17 and Block 18). The displacement $\boldsymbol{u}$ for every node of the model was stored (Block 19) and the change in volume $\Delta V$ for every one element domain was calculated (Block 20). It is assumed that the pressure calculated in the poroelastic analysis does not influence the diffusion process. At this point, the algorithm computes the change in concentrations of cells occupying the callus (Block 21). If $C_{\text {old }}$ and $V_{\text {old }}$ are respectively the concentration of cells in a given element and the volume of the same element before the distraction of the device, the concentration $C_{n e w}$ after distraction will be given by:

$$
C_{\text {new }}=C_{\text {old }} \cdot \frac{V_{\text {old }}}{V_{\text {old }}+\Delta V}
$$

The new coordinates of the nodes after the distraction process were then calculated for both the structural and diffusion models (Block 22). The algorithm then uploads the new values of concentration $C_{n e w}$ and of coordinates $\boldsymbol{C O O R D}_{\text {new }}$ into an input file (Block 23). Again the exponential law (Eqn. 4) (Block 10) and the rule of mixtures (Eqn. 5) (Block 11) were applied in order to calculate the mechanical properties for every element. At this point, the expansion of the device is terminated 
but the number of iteration iter cannot be incremented because the action of mastication loads, after the distraction, is not still simulated. For this purpose, the algorithm, after having set the variable flag equal to 1, (Block 13 and Block 24), applies the mastication loads on the modified (with new

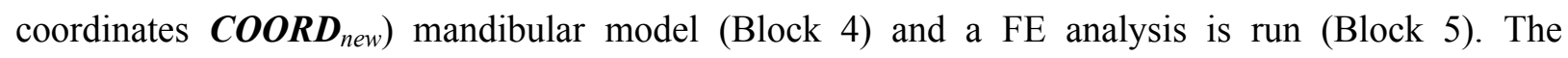
calculation of the biophysical stimulus (Block 6, Block 7, Block 8), the diffusion analysis (Block 9) and the rule of mixtures (Block 10, Block 11) follow. The biophysical stimuli by distraction and mastication are stored in a matrix, and the average of the ten previous values were chosen to determine phenotype. Since flag=1, the algorithm skips Block 13 and the number of iterations is then incremented. A new iteration of the model then commences.

\section{Results}

$0.6 \mathrm{~mm} /$ day and $1.2 \mathrm{~mm} /$ day distraction rates

The patterns of tissue differentiation are predicted to vary significantly through the thickness of the callus for both distraction rates (Fig. 4 and Fig. 5). In the first day after osteotomy, the stimulus on the posterior side of the Far Left Section (FLS) of the callus favours fibrous tissue formation, while a lower mechanical stimulus in the central region of the FLS favours bone formation. Higher values of the stimulus in the Central Section (CS) of the callus favours fibrous and cartilage tissue formation. Similarly, fibrous tissue formation is stimulated on the anterior side of the Far Right Section (FRS). After the seven day latency period a very small quantity of bone tissue is predicted to form in the centre of the CS while significant amounts of new bone tissue are predicted to form on the FLS and on the FRS. For both distraction rates a very noticeable decrease of bone tissue is predicted after the first distraction on the FLS and on the FRS, and concomitantly formation of new fibrous tissue is favoured in the CS. The Young's modulus is predicted to be lower in the CS for the faster distraction rate of $1.2 \mathrm{~mm} /$ day. During and after the distraction process large amounts of fibrous tissue are predicted to form within the centre of the fracture gap while the far left and far right sections are principally occupied by cartilaginous tissue and bone. The large amount of cartilaginous tissue 
predicted to form before and during the distraction period indicates that new bone tissue is been formed primarily via endrochondral ossification during and after distraction. Reducing the mastication loading has a significant effect on the predicted bone formation pathway, with a significant decrease in cartilage tissue formation and greater amounts of intramembranous bone formation predicted during the latency period (see Fig. 6; a similar result is observed at the $0.6 \mathrm{~mm}$ /day distraction rate). Fibrous tissue formation is still predicted in the CS with reduced mastication loads.

During the latency period, the percentage of MSCs differentiating into osteoblasts and producing new bone tissue is predicted to be greater on the FLS compared to that on the FRS (Fig. 7). The value of this difference is about $8 \%$ in the first few days and decreases to $5 \%$ in the seventh day. During the distraction period, greater amounts of bone tissue are predicted to form on the FLS of the callus compared to the FRS at a distraction rate of $0.6 \mathrm{~mm} /$ day, while smaller differences are predicted at a distraction rate of $1.2 \mathrm{~mm} /$ day. During the maturation period, the difference between the amount of bone forming on the far left section and on the far right section becomes negligible.

The percentage of cells within the entire callus differentiating into osteoblasts is predicted to increase during the latency period, while the percentage of chondrocytes and fibroblast within the callus decreases (Fig. 8). At a distraction rate of $0.6 \mathrm{~mm} /$ day, decreases of bone percentage are predicted during the first six distractions, with a slow increase in bone formation predicted during the subsequent four distractions. Conversely, at a distraction rate of $1.2 \mathrm{~mm} /$ day, the percentage of bone drops during the entire distraction process. The distraction of the device favours formation of large amounts of fibrous tissue (Fig. 8). During the maturation period, an increase of the percentage of cells differentiating into osteoblasts and a decrease of cells differentiating into fibroblasts are predicted. In general, in the distraction and maturation period, greater amounts of bone and smaller amounts of fibrous tissue form at the slower distraction rate of $0.6 \mathrm{~mm} / \mathrm{day}$, although the differences are not great. With a reduced mastication load, higher amounts of bone are predicted throughout the latency, the distraction and the maturation period (Fig. 9). By day 43 the percentages of bone and fibrous tissue within the callus are similar while negligible cartilage tissue formation is predicted. 
The formation of new bone tissue within the fracture callus can be depicted graphically (Fig. 10 and Fig. 11). The Young's modulus decreases towards the centre of the fracture callus as we move away from the adjacent bone marrow. At a distraction rate of $0.6 \mathrm{~mm} /$ day greater amounts of new bone form between the two sides of the callus.

\section{$2 \mathrm{~mm} /$ day and $3 \mathrm{~mm} /$ day distraction rates}

The percentage of cells within the callus differentiating into osteoblasts decreases significantly after the application of $2 \mathrm{~mm} /$ day and $3 \mathrm{~mm} /$ day distractions, slowly increasing during the maturation period (Figs. $12 \& 13$ ). The percentage of cells differentiating into osteoblasts for the $3 \mathrm{~mm} /$ day distraction is smaller than that predicted for all other distraction rates. Again, at these distraction rates it also appears that lower mastication loads lead to higher percentages of bone and to lower amounts of cartilage tissue formation. Comparing the percentages of bone and fibrous tissue within the callus at day 43 following the slower and these faster rates of distraction, it is predicted that increasing the rate of distraction from 0.6 to $3 \mathrm{~mm} /$ day results in progressively greater amounts of fibrous tissue formation and reduced amounts of bone tissue formation at the end of the maturation period (Fig. 14). The relative differences between the $1.2 \mathrm{~mm}$ /day and $2 \mathrm{~mm}$ /day distraction rates is less significant for lower mastication loading.

\section{Discussion}

At present a predominantly experimental approach is adopted in the study of mandibular distraction osteogenesis. $^{26,32,44,34}$ Predictive computational models can also be used to attain a better understanding of the factors which may influence the clinical procedure. The computational model presented in this paper offers a framework for studying various aspects of MSDOG, the effect of implant design, the duration of the latency period, the rate of expansion, the duration of the maturation period etc. However, this model is based on a number of assumptions and simplifications. These include the assumption that cell movement can be described using a diffusion equation (Eqn. 1) and 
that tissue differentiation is regulated by the magnitude of a biophysical stimulus $S$ (Eqn. 2), the value of which depends on the octahedral shear strain and fluid flow within the tissue. Moreover, the limits used for the biophysical stimulus $S$ (Eqn. 3) have yet to be experimentally validated, even if they are the same as those employed in previous studies that successfully predicted the patterns of tissue differentiation observed during fracture healing ${ }^{25}$ and osteochondral defect repair. ${ }^{23}$ However it is worth noting that the patterns of tissue differentiation predicted by such an algorithm were shown to be closest to experimental results compared to other mechano-regulation models. ${ }^{21}$ The model assumes an exponential increase in the Young's modulus of each tissue phenotype with time. The choice of an exponential increase in Young's modulus $E$ with time was made based on the results of Richardson et al. ${ }^{37}$ who observed an exponential increase in callus stiffness during tibial fracture healing. In reality such an exponential change in callus stiffness may be due in part to the differentiation of mesenchymal tissue into fibrous tissue, cartilage and bone, rather than the maturation of different tissue types. To the author's knowledge, besides the load-displacement curves obtained by Loboa et al $^{26}$ for distracted rat hemimandibles, little experimental data exists regarding the temporal changes in the mechanical properties of the fracture callus within an osteotomized mandible. Experimental data is however available describing the temporal changes in the mechanical properties of the fracture callus in long bones. Mora and Forriol ${ }^{33}$ measure at different time intervals the equivalent stiffness $K[\mathrm{~N} / \mathrm{mm}]$ of the bone callus generated in an osteotomized sheep bone where the fractured bones are re-joined by means of external fixators. While a comparison of these two different bone types is far from ideal when attempting to validate the model presented here, it has been observed that the predicted change in mandibular callus stiffness with time is of the same order of magnitude as that measured in long bones. An exponential model has also been used to describe the change in cartilage and fibrous tissue stiffness with time. While experimental data describing the temporal change in the mechanical properties of such soft tissues in vivo could not be found to justify the use of such a model as was done for bone, it is noted that the mechanical properties of in vitro engineered cartilage cultured using a bioreactor increase with time, with large increases observed at 
later time points ${ }^{28,29}$. It is also possible that the time scale chosen for cartilage and fibrous tissue to reach their 'normal' mechanical properties from mesenchymal tissue is incorrect, which will in turn influence the rate at which the callus stiffens and hence the rate at which endochondral ossification will occur, if indeed this process is regulated by the mechanical environment. Also, due to lack of precise experimental data, no consideration has been given to time taken for cells to differentiate from progenitor cells into fibroblasts, chondrocytes or osteoblasts. After the first simulation the model predictions state that the callus consists of a mixture of bone, cartilage and fibrous tissue (albeit with very low Young's modulus etc. due to the rule of mixtures implemented) (Figures 4-9), where it might be more accurate to state that in the first few days after the osteotomy the callus consists of progenitor cells subjected to a stimulus that if maintained will result in these cells differentiating into either fibroblasts, chondrocytes or osteoblasts, depending on the magnitude of the stimulus. This may explain why histological findings from animal model studies differ from the initial model predictions as progenitor cells take time to differentiate and produce a tissue phenotype that is recognised by appropriate histological staining. For example, significant bone and soft tissue formation is predicted during the latency period (Figures 8-9) which is not observed in histological sections taken from in vivo studies. Explicitly including in the model the time taken for mineralization etc following differentiation of progenitor cells into osteoblasts may result in model predictions more comparable to in vivo findings. However the temporal model of tissue modulus should reasonably describe the changing stiffness during this period if appropriate values of the constants $K_{i}$ and $\gamma_{i}$ (Eqn. 4) can be estimated from experimental data. Regardless, it should be highlighted that there are deviations from what is predicted by the model and what is observed in vivo at the end of the latency period, particularly the presence of soft tissue in the centre of the far left and right hand sections which is generally not observed in vivo. Possible explanations for this are given later in the text.

Concerning the finite element model, the temporo-mandibular joint is modelled by combining coupling constraints and spring elements. In reality, the mechanics and the kinematics of this articulation is more complex than that hypothesized. ${ }^{7}$ However, this same assumption has been 
adopted in a previous work ${ }^{5}$ in which good agreement was found between in vivo measurements of interdental distances and the corresponding distances measured with the numerical model. The principal parameters of the constraints used to simulate the temporo-mandibular joint have been chosen so that the finite element model predicts condilar displacements similar to those occurring in vivo during mastication. The portions of the mandible and of the device far from the distraction gap have been modelled as a 3D rigid surface. Such an assumption looses its validity if simulations were performed for longer periods ( $\sim 75$ days). However the time period investigated here (43 days) is sufficiently shorter than this threshold time. Furthermore, a preliminary numerical test has shown that the sensitivity of the strain and the pore fluid velocity to the length of the bony portion is practically negligible. The distraction process itself was modelled as a single distraction, whereas had a continuous distraction been applied to the callus during the distraction period, the predicted values of fluid flow within the callus would have reduced, which in turn would influence the predicted patterns of tissue differentiation.

The computational model predicts bone formation through both intramembranous and endochondral ossification when full mastication loading is applied to the model. Intramembranous ossification is predicted to form centripetally from the edges of the osteotomized region, which is consistent with histological observations of early bone formation in experimental studies. ${ }^{26,30}$ However in reality it is unlikely that a patient will apply full mastication loads before, during and in the days immediately after the distraction procedure. In this case primarily intramembranous bone formation and little endochondral ossification is predicted within the callus. The overall lower biophysical stimulus within the callus with reduced mastication loading results in greater amounts of bone formation, particularly in the lateral regions of the callus, however the higher stiffness of this bone tissue in these regions increases the biophysical stimulus in the centre of the callus. This results in an increase in fibrous tissue formation within this region of the callus. A number of animal model studies report intramembranous bone formation commencing at the cut bone ends with fibrous, collagenous or mesenchymal tissue within the centre of the callus after the distraction of the 
mandible. $^{22,26}$ Whether or not endochondral ossification (where bone replaces cartilage) occurs experimentally during distraction of membranous bones such as the mandible would appear to depend a number of factors such as the distraction protocol. Only scattered islands of cartilage formation are observed in some studies, ${ }^{26,40,41}$, occurring predominantly periosteally with only slight evidence of cartilage formation in the gap, while both intramembranous and endrochondal ossification are observed in others studies. ${ }^{24,30,43}$ Meyer et al. ${ }^{30}$ applied distractions of $2000 \mu$ strain, $20000 \mu$ strain, $200000 \mu$ strain or $300000 \mu$ strain (either daily or 10 times daily) in a rabbit model of mandibular distraction osteogenesis. Distraction of $20000 \mu$ strain resulted in significant amounts of cartilage formation. At lower strain magnitudes, intramembranous bone formation dominated, while histological sections exposed to higher magnitudes of strains revealed a soft collagenous tissue crossing the osteotomy gap. The rabbits were allowed to eat normally during the experiment, indicating that under certain combinations of distraction and mastication loading in the rabbit mandible, endochondral ossification occurs. The computational model presented here of the human mandible, which considers both the mastication forces and the distraction applied to the callus, predicts primarily cartilage and fibrous tissue formation in the centre of the callus with full mastication loads applied, which is similar to the histological observations from intermediate and highly distracted mandibles in a rabbit model where normal mastication is permitted. ${ }^{30}$ Conversely, with a reduced mastication load, primarily intramembranous ossification, with unusually high amounts of fibrous tissue formation in the centre of the callus, is predicted. Separate studies also report varying amounts of cartilage tissue formation in the central regions of calluses from completion of the distraction up to 4 weeks post distraction in rabbit mandibles distracted at a expansion rate of $0.36 \mathrm{~mm} /$ day. ${ }^{24}$ It should be noted that in many of the studies where cartilage formation does occur, it is not observed histologically until the end of the distraction period, however the computational model is predicting cartilage formation during the latency period. The prediction that reducing the mastication loading results in little cartilage formation suggests that the appearance of endochondral ossification in some experimental studies and not others may be partially due to differences in 
biophysical stimuli within the callus induced by the combination of different distraction and mastication loads.

It is clear therefore that the model is predicting that both the distraction and mastication loading is regulating tissue differentiation within the callus. As might be expected, the relative importance of distraction over mastication loading on regulating tissue differentiation is predicted to increase as the magnitude of the daily distraction increases. For example, the average value of the biophysical stimulus $S$ predicted within the whole callus model increases by about $12 \%$ and $51 \%$ for the distraction rates of $0.6 \mathrm{~mm} /$ day and $2 \mathrm{~mm} /$ day respectively when an intermediate distraction (fifth distraction for the rate $0.6 \mathrm{~mm} /$ day and second distraction for the rate of $2 \mathrm{~mm} /$ day) is performed. While the distraction rate significantly influences the predicted patterns of tissue differentiation during the distraction period (Fig. 8, Fig. 9, Fig. 12 \& Fig. 13), it would appear that if the distraction rate is kept below $1.2 \mathrm{~mm} /$ day, the composition of the callus at the end of the maturation period is not significantly affected (Fig. 14), indicating that at these lower distraction rates the mastication loading is the primary regulator of the final tissue types within the callus. When the mastication loading is reduced, the distraction rate can be increased to $2 \mathrm{~mm}$ /day without having a major effect on the callus composition at the end of the maturation period (Fig. 14).

Regardless of the magnitude of mastication loading, a significant increase in fibrous tissue formation is observed in the centre of the callus during the distraction period (Figures 4-6). Experimental studies have reported that distraction causes tissue damage which triggers new mesenchymal tissue formation. ${ }^{26}$ The model presented here does not explicitly include thresholds above which tissue damage will occur and where new mesenchyaml tissue will form. Instead the model predicts what cell type these progenitor cells will differentiate into based on the biophysical stimulus within the callus at that time point. Therefore the model is predicting that bone is being replaced by fibrous tissue during the distraction period, where in reality an intermediary mesenchymal tissue forms. The introduction of a new 'mesenchymal' tissue phase into the mechano-regulation model at magnitudes of the biophysical stimulus $S$ that cause failure of a particular tissue would be a 
worthwhile addition to future models.

It should be noted that during the latency period, the distraction period and beyond, the model is predicting larger than expected amounts of soft tissue within the central section of the callus, and in the centre of the far left and right-hand sections. It is only by the end of the maturation period that the two sides of the callus consist predominantly of bone, with a central section still consisting primarily of fibrous tissue, a result more akin to fibrous or delayed union than bony union. There are a number of possible specific explanations, in addition to the modelling simplifications already discussed, for this disparity between model predictions and what is observed in vivo. Firstly, although we have made every attempt to validate the finite element model, ${ }^{5,6}$ it is possible that the model is underconstrained, leading to higher than physiological predictions of the biophysical stimuli acting within the callus. This would have the effect of increasing the amount of soft tissue predicted to form within the callus. Secondly it is possible that some of the material properties used in the finite element model are not correct for the mandible, again leading to incorrect calculations of the biophysical stimuli. Thirdly it is possible that the material constants used in the model to describe the temporal change in material properties is incorrect, and that had the tissues been allowed to stiffen quicker that less soft tissue would have been predicted. Fourthly it may be that biochemical factors may also have to be introduced into the model to obtain truly accurate predictions. ${ }^{3}$ Finally it is possible that the limits used in the mechano-regulation diagram (Eqn. 3), which has been used successfully to predict patterns of tissue differentiation in long bones, ${ }^{19,23,25}$ are different for membranous bones such as the mandible, or that a different mechano-regulation hypothesis is required for such bones.

Loboa et $a l .^{26}$ used a rat model submitted to hemimandibular osteotomy to investigate tissue differentiation during distraction osteogenesis. Following a 5 day latency period a distraction protocol of $0.25 \mathrm{~mm} / 12$ hours $(0.5 \mathrm{~mm} /$ day $)$ was adopted. Using histological techniques they observed that, during the period in which the distraction is performed, increasing amounts of bone tissue form within the fracture callus. At the slower distraction rate of $0.6 \mathrm{~mm} /$ day, the computational model predicts an increase in bone tissue formation from the sixth distraction onwards (Fig. 8a). At a faster distraction 
rate of $1.2 \mathrm{~mm} /$ day, the amount of bone tissue predicted to form during the distraction process decreases throughout the entire process (Fig. 8b). Zimmermann et al. ${ }^{44}$ carried out histological analyses on the fracture callus generated in a porcine model submitted to mandibular distraction. They adopted three different rates of expansion, 1, 2 and $4 \mathrm{~mm}$ /day, and concluded that higher rates lead to smaller bone tissue percentages after the whole period of distraction. This same behaviour is also observed in the computational model (Fig. 14). At a distraction rate of $0.6 \mathrm{~mm} /$ day, the predicted percentage of bone exceeds that predicted at a distraction rate of $1.2 \mathrm{~mm} /$ day, during both the distraction and maturation period (Fig. 8). More significant reductions in bone formation are predicted when the distraction rate is increased to 2 or $3 \mathrm{~mm} /$ day (Figs. $12 \& 13$ ). Zimmermann et al. $^{44}$ find that after ten distractions at the rate of distraction of $1 \mathrm{~mm} /$ day the percentage of bone occupying the fracture gap is about $9 \%$. The percentages of bone tissue predicted after the distraction process with the computational model is similar to this experimental study. Other animal model studies report significantly higher percentages of bone at the end of the distraction period. ${ }^{26}$ Higher percentages of bone are predicted at this time point when the mastication loading is reduced.

Results show that, during the latency, the distraction and the first phases of the maturation period, greater amounts of bone tissue form on the far left section than on the far right section. This is due to the fact that the boundary conditions acting on the bone callus are asymmetric due to the occlusion on the right mandibular ramus. This boundary condition results in a reaction force and subsequently a biophysical stimulus $S$ which is greater on the far right hand side compared to the far left hand side. For more details see Appendix A. During the distraction period this difference tends to zero at a distraction rate of $1.2 \mathrm{~mm} /$ day. This is because the faster distraction rate has a more dramatic effect on the tissues differentiation process throughout the entire callus compared to the slower rate. In other words, the biophysical stimulus $S$ tends to be asymmetric (i.e. closer to that in which no distractions are performed) at a lower distraction rate of $0.6 \mathrm{~mm} /$ day rather than with a higher distraction rate of $1.2 \mathrm{~mm} /$ day. The difference between the amount of bone localized on the far left section and on the far right section becomes negligible as the healing progresses (Fig. 7a, 7b). 
It was found that at a distraction rate of $1.2 \mathrm{~mm} /$ day a lower callus Young's modulus is predicted compared to the $0.6 \mathrm{~mm} /$ day distraction rate (Figs. $4 \& 5$ ). This is due to a reduction in cell number and an increase in soft tissue formation during distraction. At a slower distraction rate of 0.6 $\mathrm{mm} /$ day, the cells have a smaller callus volume to diffuse into and then differentiate. The lower expansion rate of $0.6 \mathrm{~mm} /$ day also leads to greater amounts of bone tissue 'bridging' the left and right sides of the callus (Figs. $10 \& 11$ ). It is possible that excessive bone quantities in this area may hinder the process of distraction because a premature bone union can occur. Therefore a faster distraction rate of $1.2 \mathrm{~mm} /$ day is preferable in cases when there is an increased risk of bone union. Finally it is predicted that distraction rates higher than $1.2 \mathrm{~mm}$ /day can lead to the formation of low quality bone callus (Figs. $12 \& 13$ ). Therefore a distraction rate of $1.2 \mathrm{~mm} /$ day is suggested as an optimal distraction rate, as slower rates of distraction may lead to the problems of premature bone bridging discussed previously. It appears that mastication loading has a significant effect of the predicted bone formation pathway (Figs. $8 \&$ 9, Figs. $12 \& 13$ ). Reducing the mastication loading leads to higher amounts of bone and therefore to a faster healing process. Based on these results, one could conclude that a liquid diet could accelerate the fracture repair process. It may also be possible to increase the distraction rate slightly if the mastication loading is reduced, without significantly influencing the final tissue phenotype compared to slower distraction rates. 


\section{References}

1 Anderson, C.B. Mechanics of fluids. In: Baumeister, T. (Ed.), Marks' Saturated Handbook of Mechanical Engineers, pp. 3.48-3.76, 1967.

2 Andreykiv, A., P.J. Prendergast, F. van Keulen, W. Swieszkowski and P.M. Rozing. Bone ingrowth simulation for a concept glenoid component design. J. Biomech. 38: 1023-1033, 2005.

3 Bailon-Plaza A, van der Meulen MC. A mathematical framework to study the effects of growth factor influences on fracture healing. J. Theor. Biol. 212:191-209, 2001.

4 Basciftci, F.A., H.H. Korkmaz, H. Işeri and S. Malkoç. Biomechanical evaluation of mandibular midline distraction osteogenesis by using finite element method. Am. J. Orthod. Dentofac. 125: 706715, 2004.

5 Boccaccio, A., L. Lamberti, C. Pappalettere, A. Carano and M. Cozzani. Mechanical behaviour of an osteotomized mandible with distraction orthodontic devices. J. Biomech. 39: 2907-2918, 2006.

6 Boccaccio, A., L. Lamberti, C. Pappalettere, M. Cozzani and G. Siciliani. Comparison of different orthodontic devices for Mandibular Symphyseal Distraction Osteogenesis: a finite element study. Am. J. Orthod. Dentofac. In press, 2006.

7 Beek, M., J.H. Koolstra, L.J. Van Ruijven and T.M.G.J. Van Eijden. Three-dimensional finite element analysis of the human temporomandibular joint disc. J. Biomech. 33: 307-316, 2000.

8 Carter, D.R., P.R. Blenman and G.S. Beaupré. Correlations between mechanical stress history and tissue differentiation in initial fracture healing. J. Orthop. Res. 6: 736-748, 1998.

9 Claes, L.E. and C.A. Heigele. Magnitudes of local stress and strain along bony surfaces predict the course and type of fracture healing. J. Biomech. 32: 255-266, 1999.

10 Conley, R. and H. Legan. Mandibular symphyseal distraction osteogenesis: diagnosis and treatment planning considerations. Angle Orthod. 73: 3-11, 2003.

11 Conley, R. and H. Legan. Correction of severe obstructive sleep apnea with bimaxillary transverse distraction osteogenesis and maxillomandibular advancement. Am. J. Orthod. Dentofac. 129: 283-292, 2006.

12 Cowin, S.C. Bone poroelasticity. J. Biomech. 32, 217-238, 1999.

13 Faulkner, M.G., D.C. Hatcher, and A. Hay. A three-dimensional investigation of temporomandibular joint loading. J. Biomech. 20: 997-1002, 1987.

14 Del Santo, M., C.A. Guerrero, P.H. Buschang, J. English, L. Samchukov and W. Bell. Long-term skeletal and dental effects of mandibular symphyseal distraction osteogenesis. Am. J. Orthod. Dentofac. 118, 485-493, 2000.

15 Gòmez-Benito, M.J., J.M. Garcìa-Aznar, J.H. Kuiper and M. Doblaré. Influence of fracture gap size on the pattern of long bone healing: a computational study. J. Theor. Biol.235: 105-109, 2005.

16 Guerrero, C.A. Expansion mandibular quirurgica. Revista Venezolana de Ortodoncia 1: 48-50. (In Spanish) English translation "Rapid mandibular expansion", 1990.

17 Guerrero, C.A., W.H. Bell, G.I. Contasti and A.M. Rodriguez. Mandibular widening by intraoral 
distraction osteogenesis. Brit. J. Oral Max. Surg. 35: 383-92, 1997.

Hori, R.Y. and J.L. Lewis. Mechanical properties of the fibrous tissue found at the bone cement interface following total joint replacement. J. Biomed. Mater. Res. 16: 911-927, 1982.

Huiskes, R., W.D. van Driel, P.J. Prendergast, and K. Søballe. A biomechanical regulatory model of periprosthetic tissue differentiation. J. Mater. Sci. Mater. Med. 8: 785-788, 1997. Imola, J.M. Craniofacial distraction osteogenesis. http://www.emedicine.com/ent/topic702.htm, 2004 Isaksson, H., C.C. van Donkelaar, R. Huiskes and K. Ito. Corroboration of mechano-regulatory algorithms for tissue differentiation during fracture healing: comparison with in vivo results. J. Orthop. Res., In Press, 2006.

22 Karp N.S., J.G. McCarthy, J.S. Schreiber, H.A. Sisson and C.H. Thorne. Membranous bone lengthening: A serial histological study. Ann. Plast. Surg. 29: 2, 1992.

23 Kelly, D.J. and P.J. Prendergast. Mechano-regulation of stem cell differentiation and tissue regeneration in osteochondral defects. J. Biomech. 38: 1413-1422, 2005.

24 Komuro, Y., T. Takato, K. Harii. The histologic analysis of distraction osteogenesis of the mandible in rabbits. Plast. Reconst. Surg. 94:152, 1994.

25 Lacroix, D. and P.J. Prendergast. A mechano-regulation model for tissue differentiation during fracture healing: analysis of gap size and loading. J. Biomech. 35, 1163-1171, 2002.

26 Loboa, E.G., T.D. Fang, S.M. Warren, D.P. Lindsey, K.D. Fong, M.T. Longaker and D.R. Carter. Mechanobiology of mandibular distraction osteogenesis: experimental analyses with a rat model. Bone 34: 336-343, 2004.

27 Loboa, E.G., T.D. Fang, D.W. Parker, Warren, S.M., K.D. Fong, M.T. Longaker and D.R. Carter. Mechanobiology of mandibular distraction osteogenesis: finite element analyses with a rat model. $J$. Orthop. Res. 23: 663-670, 2005.

28 Martin, I., Obradovic, B., Treppo, S., Grodzinsky, A.J., Langer, R., Freed, L.E., Vunjak-Novakovic G. Modulation of the mechanical properties of tissue engineered cartilage. Biorheology 37: 141-147, 2000 .

29 Mauck, R.L., Soltz, M.A., Wang, C.C., Wong, D.D., Chao, P.H., Valhmu, W.B., Hung, C.T., Ateshian, G.A. Functional tissue engineering of articular cartilage through dynamic loading of chondrocyteseeded agarose gels. J. Biomech. Eng. 122: 252-60, 2000.

30 Meyer, U., T. Meyer, H.P. Wiesmann, B. Kruse-Lösler, D. Vollmer, U. Stratmann, U. Joos. Mechanical tension in distraction osteogenesis regulates chondrocytic differentiation. Int. J. Oral Max. Surg. 30: 522-530, 2001.

31 Meyer, U., J. Kleinheinz, U. Joos. Biomechanical and clinical implications of distraction osteogenesis in craniofacial surgery. J. Cranio Maxill. Surg. 32, 140-149, 2004.

32 Meyer, U., Kruse-Lösler, B., Wiesmann, H.P. Principles of bone formation driven by biophysical forces in craniofacial surgery. British Journal of Oral and Maxillofacial Surgery, 44, 289-295, 2006.

33 Mora, G. and F. Forriol. Mechanical analysis of the healing of different osteotomies fixed externally. 
Int. Orthop. 24, 295-298, 2000.

34 Paccione, M.F., B.J. Mehrara, S.M. Warren, J.A. Greenwald, J.A. Spector, J.S. Luchs, et al.. Rat mandibular distraction osteogenesis: latency, rate and rhythm determine the adaptive response. $J$. Cranio Maxill. Surg. 12: 175-182, 2001.

35 Pauwels, F., 1960. Eine neue theorie über den einflu $\beta$ mechanischer reize auf die differenzierung der stützgewebe. Z Anat Entwickl. Gesch. 121, 478-515. Translated as A new theory concerning the influence of mechanical stimuli on the differentiation of the supporting tissues. In: Maquet, P., Furlong, R., (Eds) Bioechanics of the Locomotor apparatus, Springer, Berlin, 1980, pp. 375-407.

36 Prendergast, P.J., R. Huiskes and K. Søballe. Biophisical stimuli on cells during tissue differentiation at implant interfaces. J. Biomech. 30: 539-548, 1997.

37 Richardson, J.B., J. Kenwright and J.L. Cunningham. Fracture stiffness measurement in the assessment and management of tibial fractures. J. Clin. Biomech. 7: 75-79, 1992.

38 Schaffer, M.B. and D.B. Burr. Stiffness of compact bone: effects of porosity and density. J. Biomech. 21: 13-16, 1988.

39 Schwartz-Dabney, C.L. and P.C. Dechow. Variations in cortical material properties throughout the human dentate mandible. Am. J. Phys. Anthropol. 120: 252-277, 2003.

40 Stewart, K.J., G.O. Lvoff, S.A. White, S.F. Bonar, W.R. Walsh, R.C. Smart and M.D. Poole. Mandibular distraction osteogenesis: a comparison of distraction rates in the rabbit model. J. Cranio Maxill. Surg. 26: 43-49, 1998.

41 Tavakoli, K., W.R. Walsh, F. Bonar, R. Smart, S. Wulf and M.D. Poole. The role of latency in mandibular osteodistraction. J. Cranio Maxill. Surg. 26: 209-219, 1998.

42 Weil, T.S., J. Van Sickles and J. Payne. Distraction osteogenesis for correction of transverse mandibular deficiency: a preliminary report. J. Oral. Maxillofac. Surg. 55: 953-960, 1997.

43 Yazawa, M., K. Kishi, H. Nakajima, T. Nakajima. Expression of bone morphogenetic proteins during mandibular distraction osteogenesis in rabbits. J.Oral Maxillofac. Surg. 61: 587-592, 2003.

44 Zimmermann, C.E., P. Thurmüller, M.J. Troulis, D.H. Perrot, B. Rahn and L.B. Kaban. Histology of the porcine mandibular distraction wound. Int. J. Oral Max. Surg. 34: 411-419, 2005.

45 Hibbit, Karlsson \& Sorensen, ABAQUS ${ }^{\circledR} 6.4$ User's Manual, 2004. 


\section{TABLES}

Table 1: Values of the parameters $K_{i}$ and $\gamma_{i}$ used in equation (4).

\begin{tabular}{|ccc|}
\hline \hline MATERIAL & $K_{i}[\mathrm{MPa}]$ & $\gamma_{i}\left[\right.$ iteration $\left.^{-1}\right]$ \\
\hline \hline CARTILAGE & 0.198 & 0.011 \\
IMMATURE BONE & 0.195 & 0.023 \\
FIBROUS TISSUE & 0.2 & 0.0063 \\
MATURE BONE & 0.194 & 0.03 \\
\hline
\end{tabular}

Table 2. Number and type of elements adopted in the Finite Element analysis

\begin{tabular}{cccc}
\hline ANATOMICAL DISTRICT & NUMBER & NAME & TYPE \\
\hline \hline $\begin{array}{c}\text { MANDIBULAR BONE FAR } \\
\text { FROM THE OSTETOMIZED } \\
\text { REGION }\end{array}$ & 12375 & R3D3 & 3 nodes 3D rigid elements triangular facets \\
$\begin{array}{c}\text { MANDIBULAR BONE NEAR } \\
\text { TO THE OSTEOTOMIZED } \\
\text { REGION }\end{array}$ & 2696 & C3D8P & 8-node trilinear displacement and pore pressure \\
BONE CALLUS & 2696 & C3D8P & 8-node trilinear displacement and pore pressure \\
\hline \hline
\end{tabular}

Table 3. Material properties utilized in FEM analyses for the bone callus 1, 8, 11, 17, 24, 35

\begin{tabular}{|c|c|c|c|c|c|}
\hline Material & $\begin{array}{c}\text { Granulation } \\
\text { tissue }\end{array}$ & Fibrous tissue & Cartilage & $\begin{array}{c}\text { Immature } \\
\text { bone }\end{array}$ & Mature bone \\
\hline \multirow{6}{*}{$\begin{array}{c}\text { Young' Modulus } \\
\text { [MPa] } \\
\text { Permeability } \\
{\left[\mathrm{m}^{4} / \mathrm{Ns}\right]} \\
\text { Poisson's Ratio } \\
\text { Bulk Modulus Grain } \\
\text { [MPa] } \\
\text { Bulk Modulus Liquid } \\
\text { [MPa] } \\
\text { Porosity }\end{array}$} & 0.2 & $\overline{22}$ & 10 & 1000 & 6000 \\
\hline & $1 * 10^{-14}$ & $1 * 10^{-14}$ & $5 * 10^{-15}$ & $1 * 10^{-13}$ & $3.7 * 10^{-13}$ \\
\hline & 0.167 & 0.167 & 0.167 & 0.3 & 0.3 \\
\hline & 2300 & 2300 & 3400 & 13920 & 13920 \\
\hline & 2300 & 2300 & 2300 & 2300 & 2300 \\
\hline & 0.8 & 0.8 & 0.8 & 0.8 & 0.8 \\
\hline
\end{tabular}



was generated; (b) mandible-DOD FEM model, illustrating the coordinate system utilized. (c) FEM model of the osteotomized zone. Different regions and materials included in the model: (d) cortical bone and principal material directions, (e) cancellous bone, (f) fracture callus.

Figure 2. (a) Loads and constraints utilized in FEM analysis: (b) details of the temporo-mandibular joint, (c) details of the device during the mastication phase, (d) details of the device during the expansion process (e) details of the unilateral occlusion on the second premolar

Figure 3. Schematic of the implemented mechano-regulation algorithm.

Figure 4. Three different sagittal sections through the thickness of the callus were considered, the far left section (FLS), the central section (CS) and the far right section (FRS); for each of them the patterns of tissue differentiation are predicted. Patterns of tissue differentiation predicted with the mechano-regulation algorithm at a distraction rate of $0.6 \mathrm{~mm} /$ day. The sections considered lie on a plane parallel to the plane 2-3 shown in Fig. 1b. Full mastication loads are applied.

Figure 5. Three different sagittal sections through the thickness of the callus were considered, the far left section (FLS), the central section (CS) and the far right section (FRS); for each of them the patterns of tissue differentiation are predicted. Patterns of tissue differentiation predicted with the mechano-regulation algorithm at a distraction rate of $1.2 \mathrm{~mm}$ /day. The sections considered lie on a plane parallel to the plane 2-3 shown in Fig. 1b. Full mastication loads are applied.

Figure 6. Three different sagittal sections through the thickness of the callus were considered, the far left section (FLS), the central section (CS) and the far right section (FRS); for each of them the patterns of tissue differentiation are predicted. Patterns of tissue differentiation predicted with the mechano-regulation algorithm at a distraction rate of $1.2 \mathrm{~mm} /$ day. The sections considered lie on a plane parallel to the plane 2-3 shown in Fig. 1b. Mastication loads reduced by $70 \%$ are applied.

Figure 7. Bone percentage on the Far Left Section (FLS), Far Right Section (FRS) and Central Section (CS) during the latency period (LP), the distraction period (DP) and the maturation period (MP) and for both distraction rates: (a) $0.6 \mathrm{~mm} /$ day and (b) $1.2 \mathrm{~mm}$ /day. Every 5 iterations correspond to 1 day. Full mastication loads are applied. 
Figure 8. Percentage values of the tissues composing the bone callus in the latency period (LP), distraction period (DP) and maturation period (MP), for both distraction rates: (a) $0.6 \mathrm{~mm} /$ day and (b) $1.2 \mathrm{~mm} /$ day. Every 5 iterations correspond to 1 day. Full mastication loads are applied.

Figure 9. Percentage values of the tissues composing the bone callus in the latency period (LP), distraction period (DP) and maturation period (MP), for both the two distraction rates: (a) $0.6 \mathrm{~mm} /$ day and (b) $1.2 \mathrm{~mm} /$ day. Every 5 iterations correspond to 1 day. Mastication loads reduced by $70 \%$ are applied.

Figure 10. Bone regeneration process for a distraction rate of $0.6 \mathrm{~mm} / \mathrm{day}$.

Figure 11. Bone regeneration process for a distraction rate of $1.2 \mathrm{~mm} /$ day.

Figure 12. Percentage values of the tissues composing the bone callus in the latency period (LP), distraction period (DP) and maturation period (MP), for the distraction rates of: (a) $2.0 \mathrm{~mm} /$ day and (b) $3.0 \mathrm{~mm} /$ day. Every 5 iterations correspond to 1 day. Full mastication loads are applied.

Figure 13. Percentage values of the tissues composing the bone callus in the latency period (LP), distraction period (DP) and maturation period (MP), for the distraction rates of: (a) $2.0 \mathrm{~mm} /$ day and (b) $3.0 \mathrm{~mm} /$ day. Every 5 iterations correspond to 1 day. Mastication loads reduced by $70 \%$ are applied.

Figure 14. Amounts of bone and fibrous tissue predicted by the numerical model after 43 days since the osteotomy for both, the full and the reduced mastication loading. The higher amounts of bone bridging the callus for a distraction rate of $0.6 \mathrm{~mm} /$ day indicate a higher risk of a premature bone union. On the other hand, the significant percentage of fibrous tissue for distraction rates of $2 \mathrm{~mm} /$ day and $3 \mathrm{~mm} /$ day indicate the formation of a low quality bone callus. Therefore, the rate of $1.2 \mathrm{~mm} /$ day could be considered the optimal distraction rate as it is the best compromise between the risk of a premature bone union and the risk of a fibrous union.

Figure A1. Evaluation of the reaction force acting on the left and on the right side of the bone callus. 


\section{APPENDIX A EVALUATION OF THE REACTION FORCE ACTING ON THE BONE CALLUS}

The boundary and loading conditions acting on the mandibular arch may be schematized with the simplified structure S1 illustrated in Fig. A1. The domain indicated with LA represents the left arm of the mandible while the $\mathrm{BC}$ and $\mathrm{RA}$ domains represent the bone callus and the right arm respectively. The unilateral occlusion is schematized with the UO supports. We assume, for simplicity, that the UO supports prevent displacements in all three coordinate directions. (In the FE model, the constraint simulating the unilateral occlusion only prevents displacement along the 3 direction, while the other two degrees of freedom are restrained due to the elastic element simulating the temporo-mandibular joint.) Let $\boldsymbol{F}_{\boldsymbol{m} \boldsymbol{L}}$ and $\boldsymbol{F}_{\boldsymbol{m} \boldsymbol{R}}$ be the vertical components (which are the most significant component) of the resultant forces developed by the mastication muscles on the left and on the right side and let $b$ be the distance of the action line of $\boldsymbol{F}_{\boldsymbol{m} \boldsymbol{L}}$ force with respect to the bone callus domain; $c$ is the thickness of the $\mathrm{BC}$ bone callus.

Let us suppose RA and LA to be rigid structures. This allows us to model the S1 structure as shown in structure S2. The action of the $\boldsymbol{F}_{\boldsymbol{m} \boldsymbol{L}}$ force on the left side of BC is given by the same $\boldsymbol{F}_{\boldsymbol{m} \boldsymbol{L}}$ force and a moment $M_{L}$ on the left hand side of the callus is given by: $M_{L}=F_{m L} * b$. The moment on the right hand side is given by $M_{R}=M_{L}+F_{m L} * c=F_{m L} *(b+c)$. Therefore in general, the reaction force acting on the right side of the callus is bigger than the left side.

As is clear, the real boundary and loading conditions of the mandible are more complicated than those schematized in S1. In fact, we neglect the effect of the constraint simulating the temporomandibular joint and we introduce the simplification that the support modelling the unilateral occlusion prevents displacement in all the three coordinate directions. However, the hypothesis made should not affect the validity of the conclusion. 


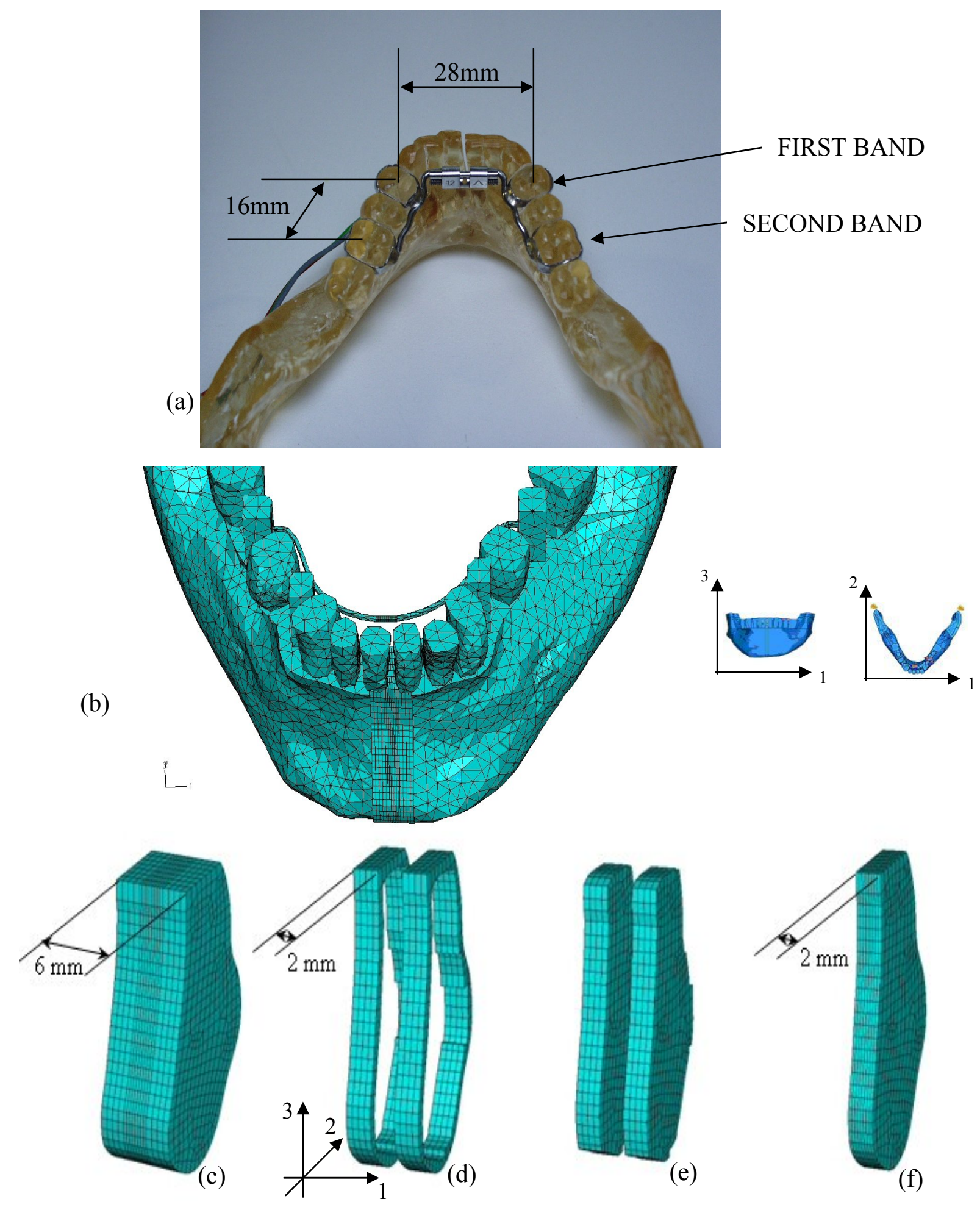

Figure 1. (a) Photoelastic model -built with Rapid Prototyping techniques- for which the FE model was generated; (b) mandible-DOD FEM model, illustrating the coordinate system utilized. (c) FEM model of the osteotomized zone. Different regions and materials included in the model: (d) cortical bone and principal material directions, (e) cancellous bone, (f) fracture callus. 


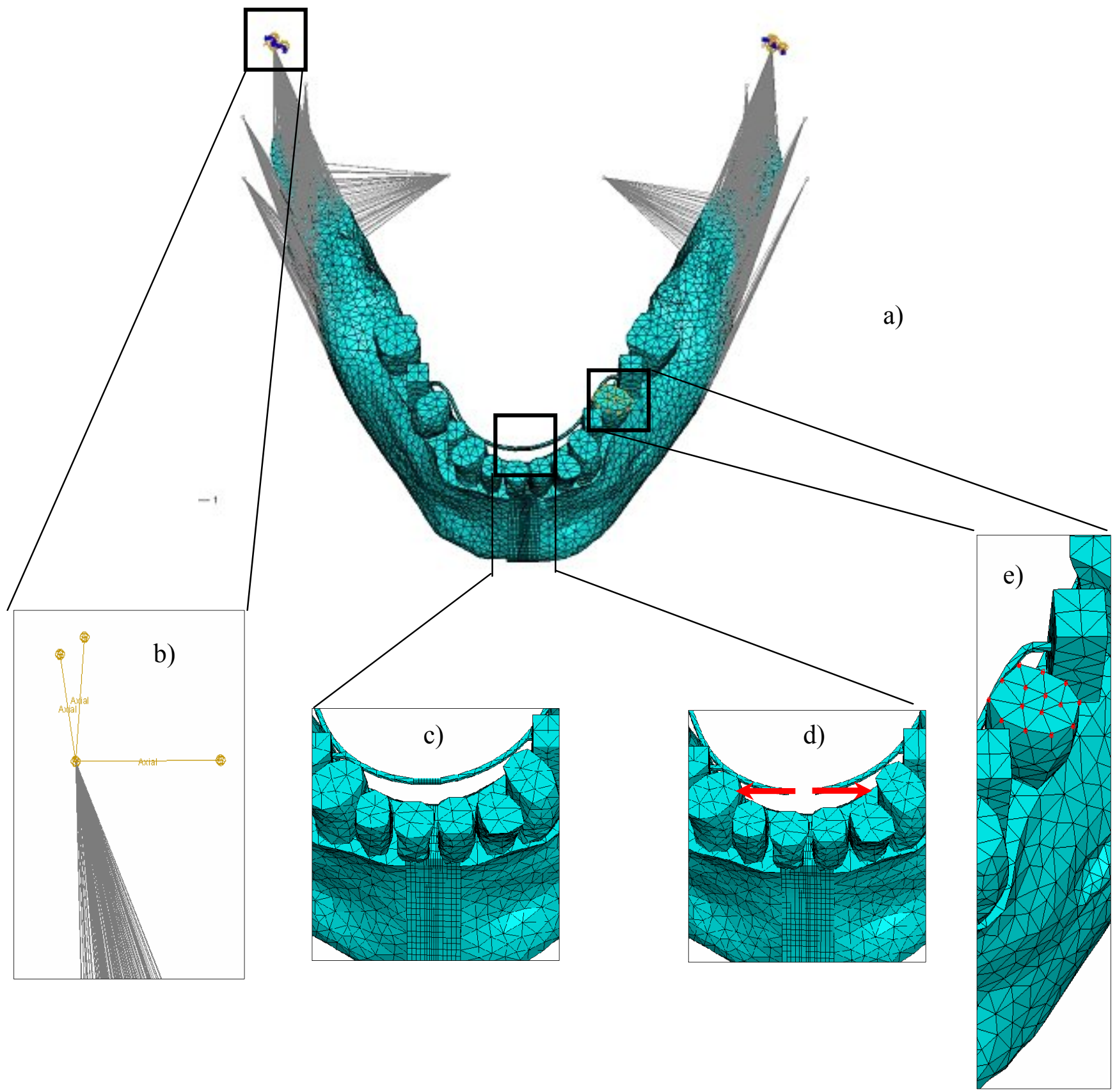

Figure 2. (a) Loads and constraints utilized in FEM analysis: (b) details of the temporomandibular joint, (c) details of the device during the mastication phase, (d) details of the device during the expansion process (e) details of the unilateral occlusion on the second premolar 


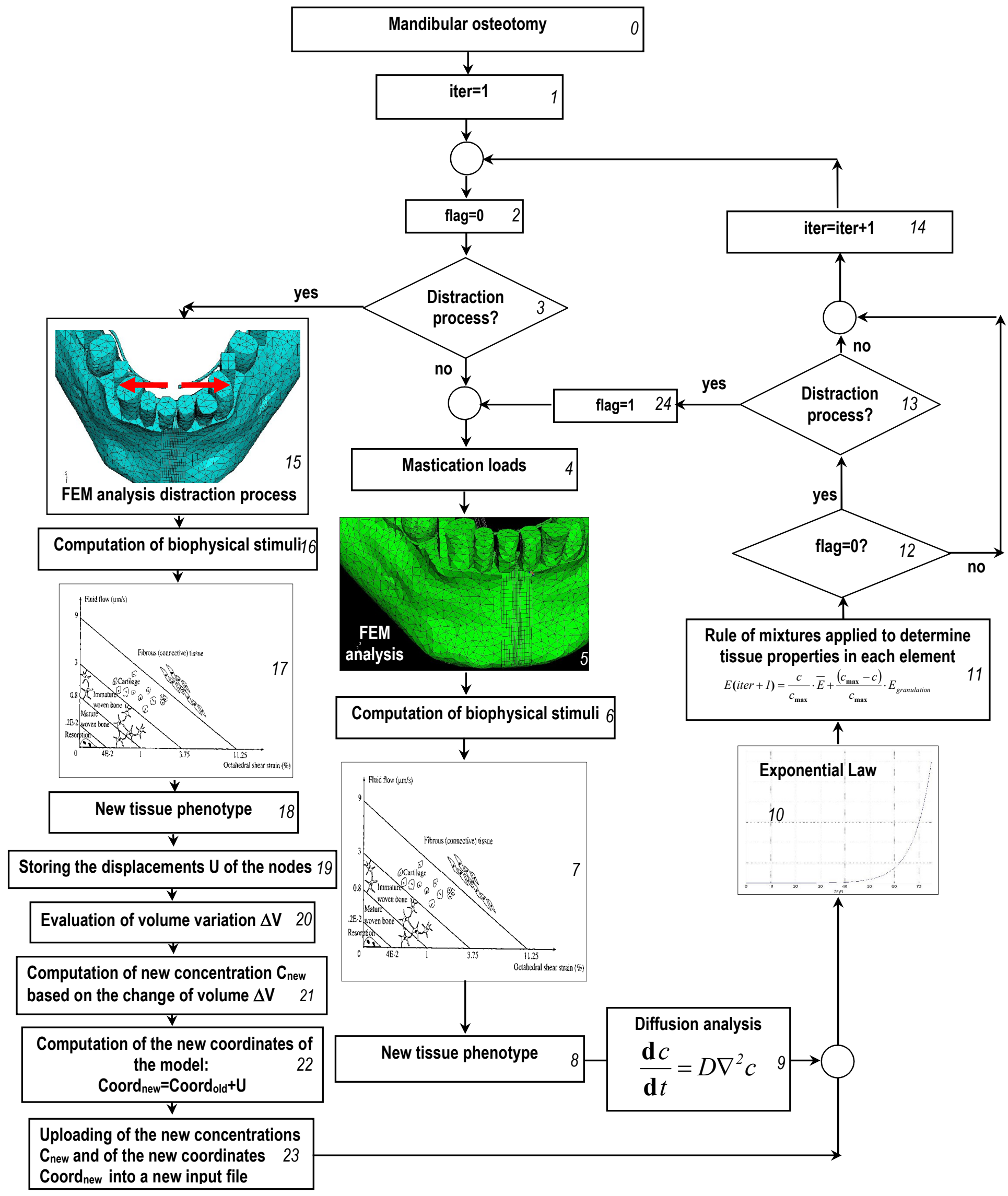

Figure 3. Schematic of the implemented mechano-regulation algorithm 


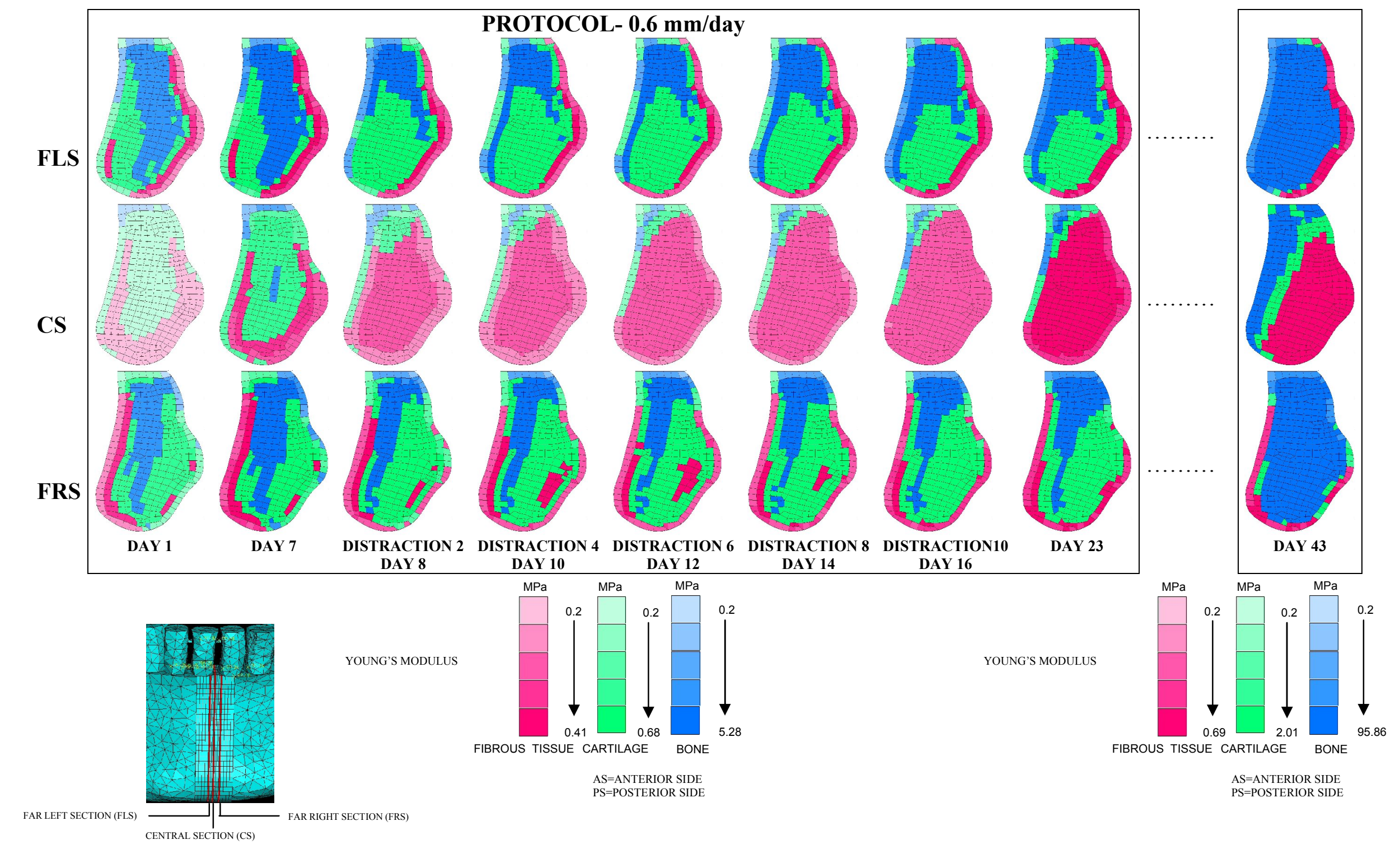

Figure 4. Three different sagittal sections through the thickness of the callus were considered, the far left section (FLS), the central section (CS) and the far right section (FRS); for each of them the patterns of tissue differentiation are predicted. Patterns of tissue differentiation predicted with the mechano-regulation algorithm at a distraction rate of $0.6 \mathrm{~mm} / \mathrm{day}$. The sections considered lie on a plane parallel to the plane 2-3 shown in Fig. 1b. Full mastication loads are applied. 


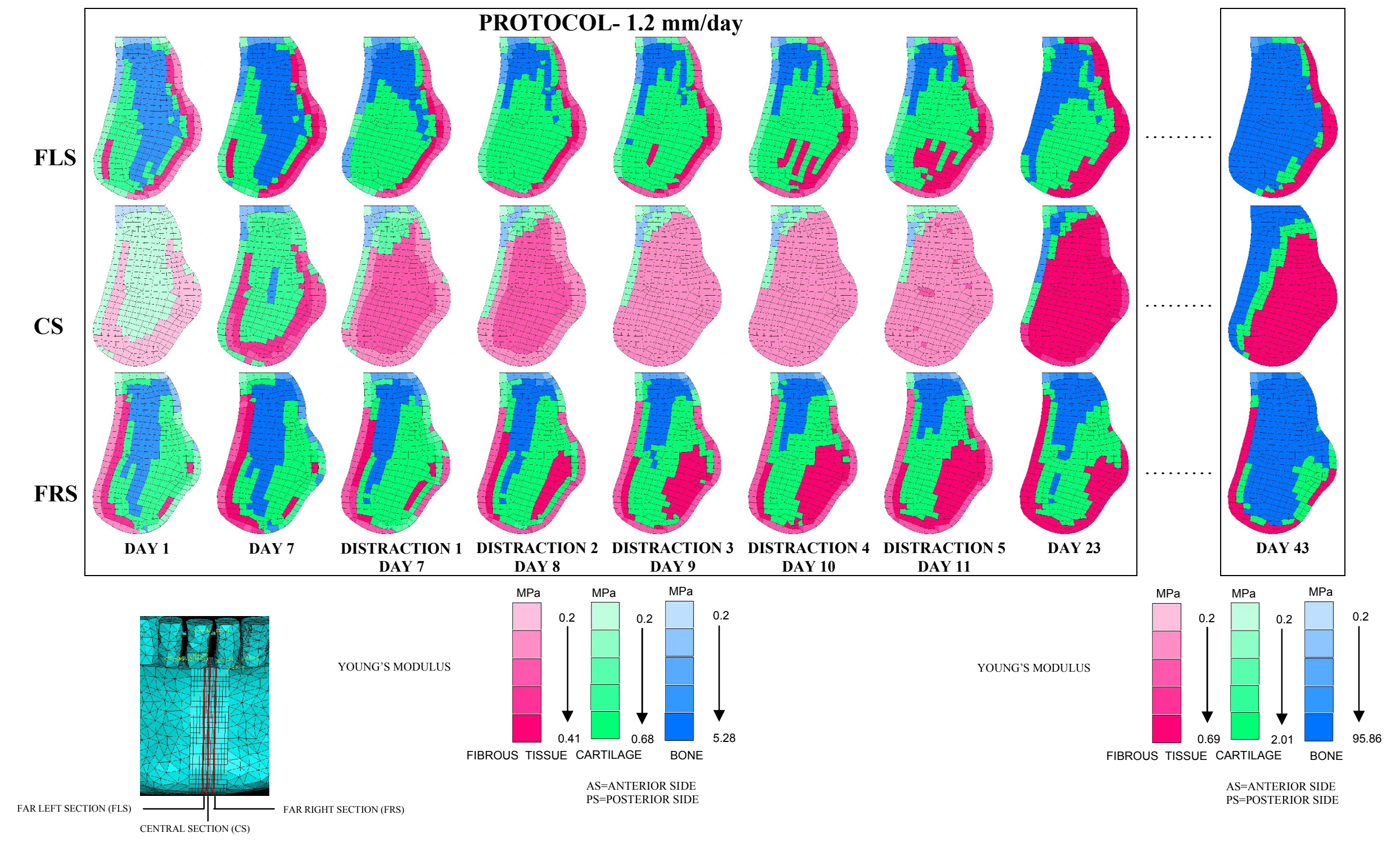

Figure 5. Three different sagittal sections through the thickness of the callus were considered, the far left section (FLS), the central section (CS) and the far right section (FRS); for each of them the patterns of tissue differentiation are predicted. Patterns of tissue differentiation predicted with the mechano-regulation algorithm at a distraction rate of $1.2 \mathrm{~mm} / \mathrm{day}$. The sections considered lie on a plane parallel to the plane 2-3 shown in Fig. 1b. Full mastication loads are applied. 


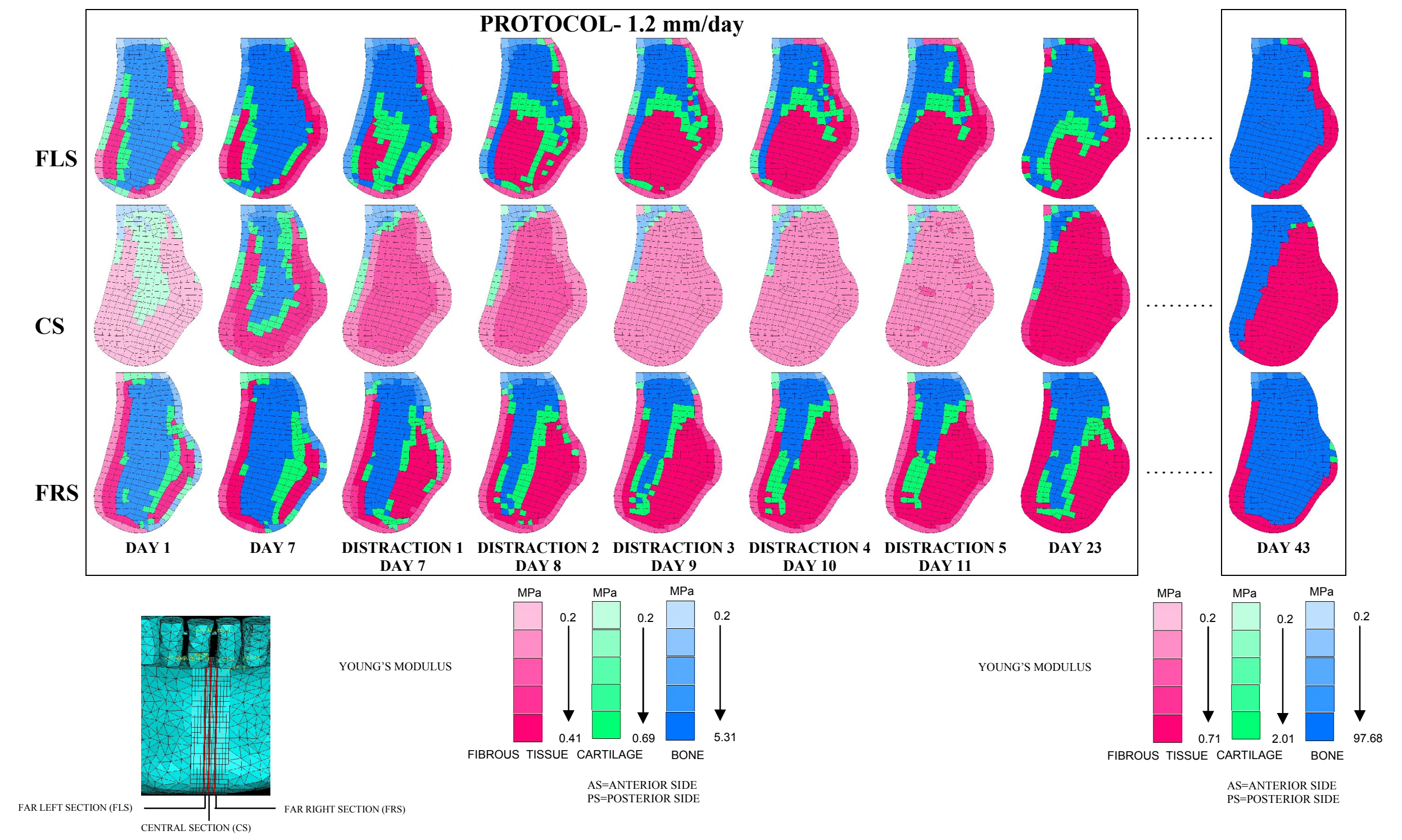

Figure 6. Three different sagittal sections through the thickness of the callus were considered, the far left section (FLS), the central section (CS) and the far right section (FRS); for each of them the patterns of tissue differentiation are predicted. Patterns of tissue differentiation predicted with the mechano-regulation algorithm at a distraction rate of $1.2 \mathrm{~mm} / \mathrm{day}$. The sections considered lie on a plane parallel to the plane 2-3 shown in Fig. 1b. Mastication loads reduced by $70 \%$ are applied. 


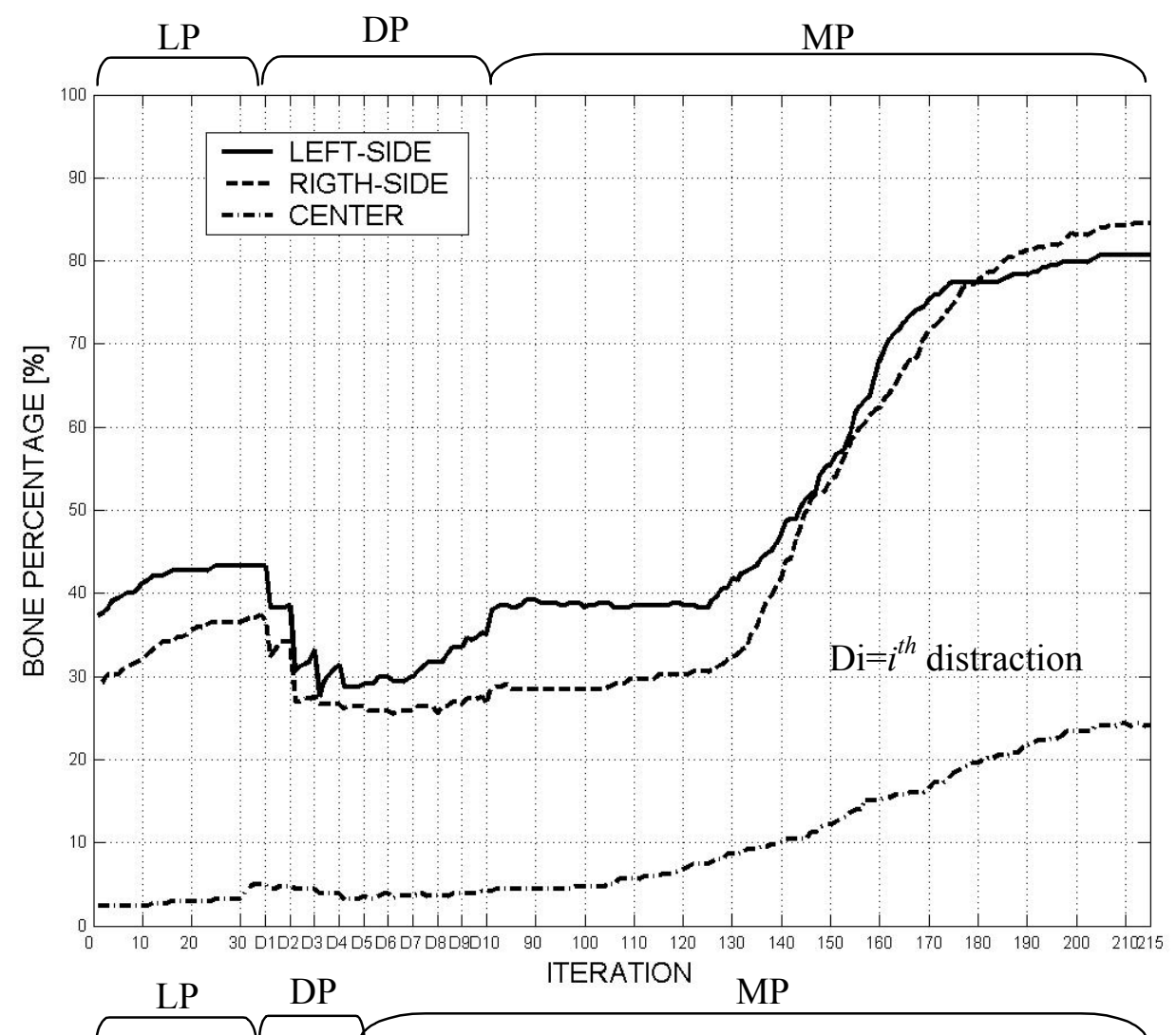

a)

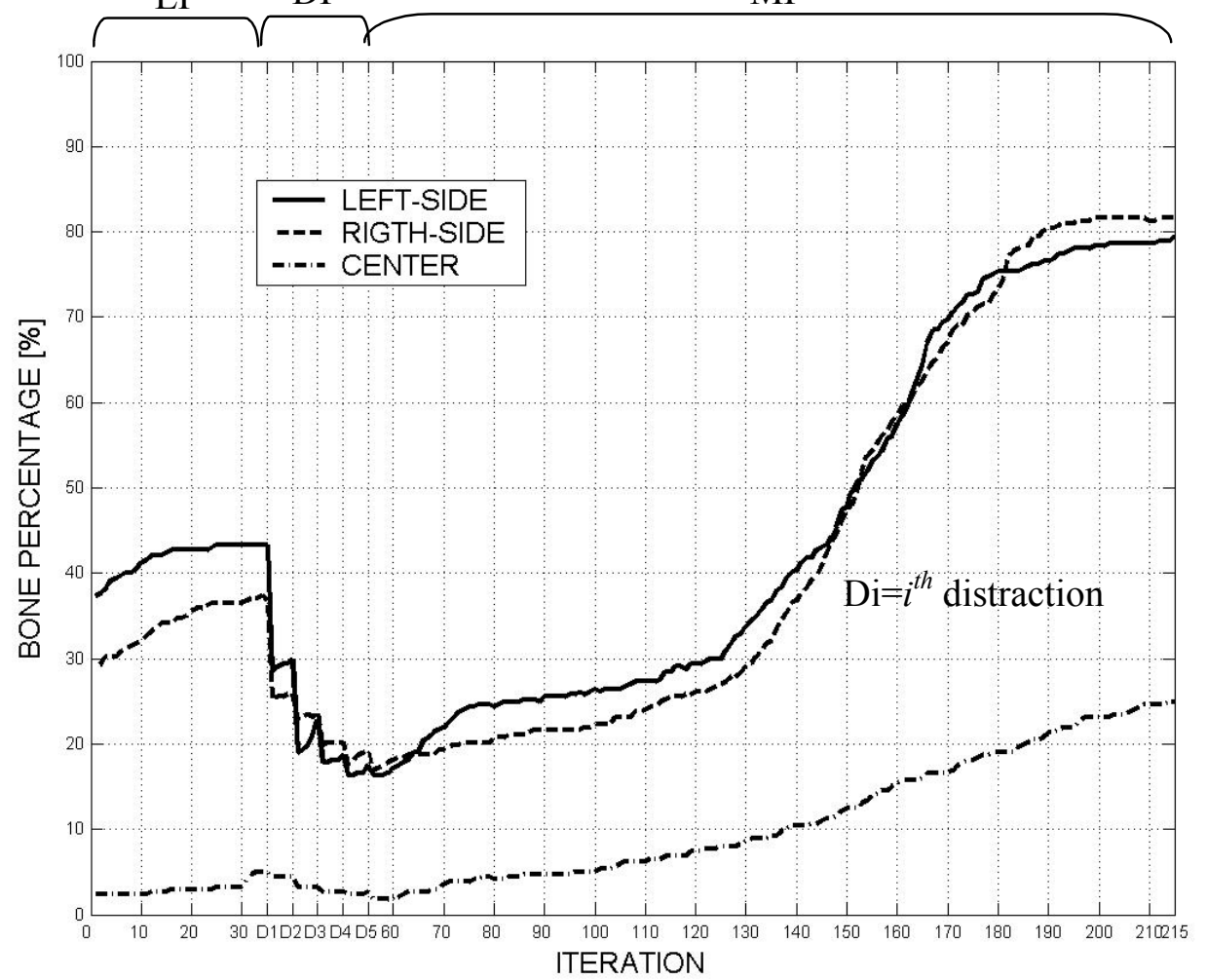

b)

Figure 7. Bone percentage on the Far Left Section (FLS), Far Right Section (FRS) and Central Section (CS) during the latency period (LP), the distraction period (DP) and the maturation period (MP) and for both distraction rates: (a) $0.6 \mathrm{~mm} /$ day and (b) $1.2 \mathrm{~mm} /$ day. Every 5 iterations correspond to 1 day. Full mastication loads are applied. 


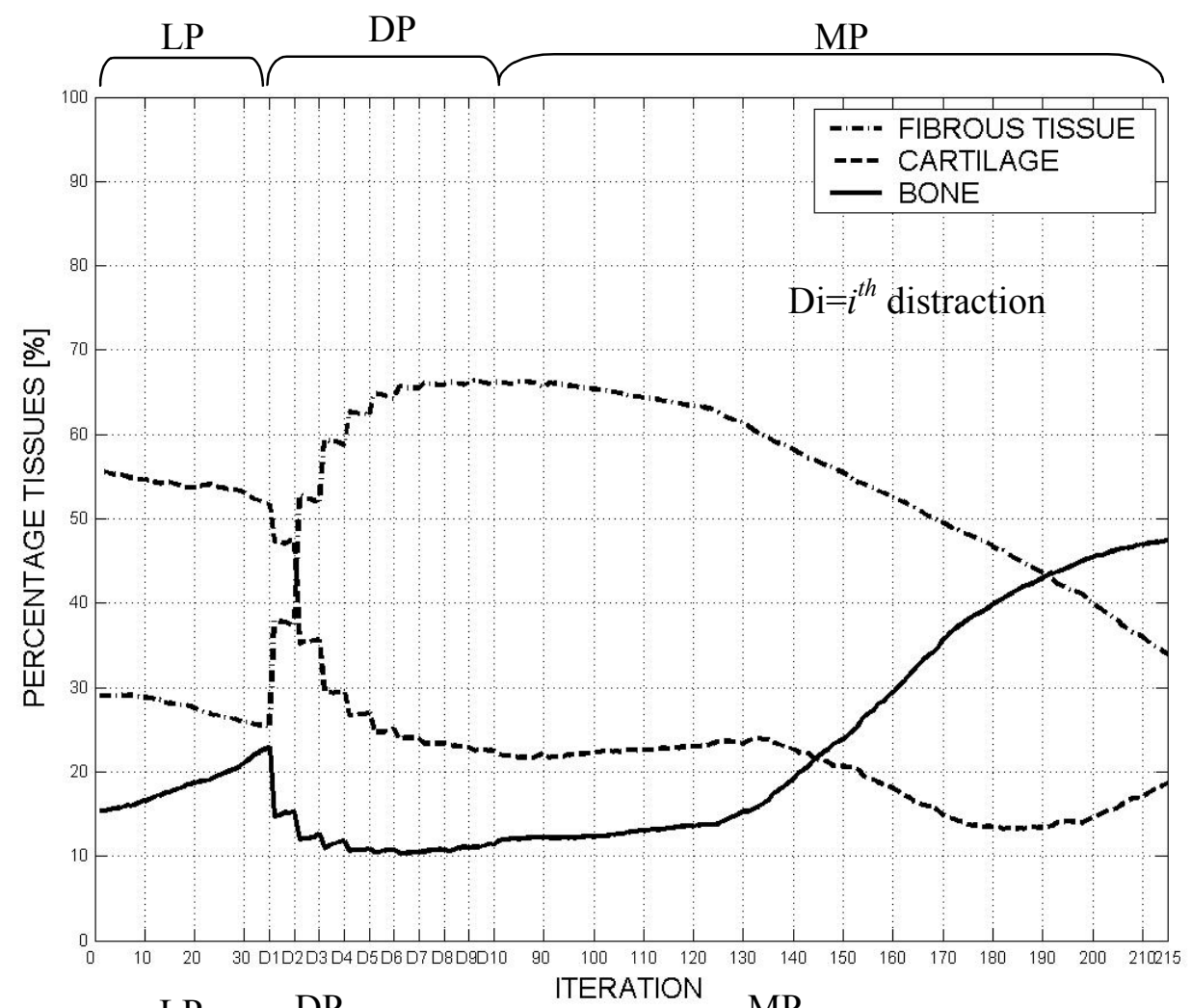

a)

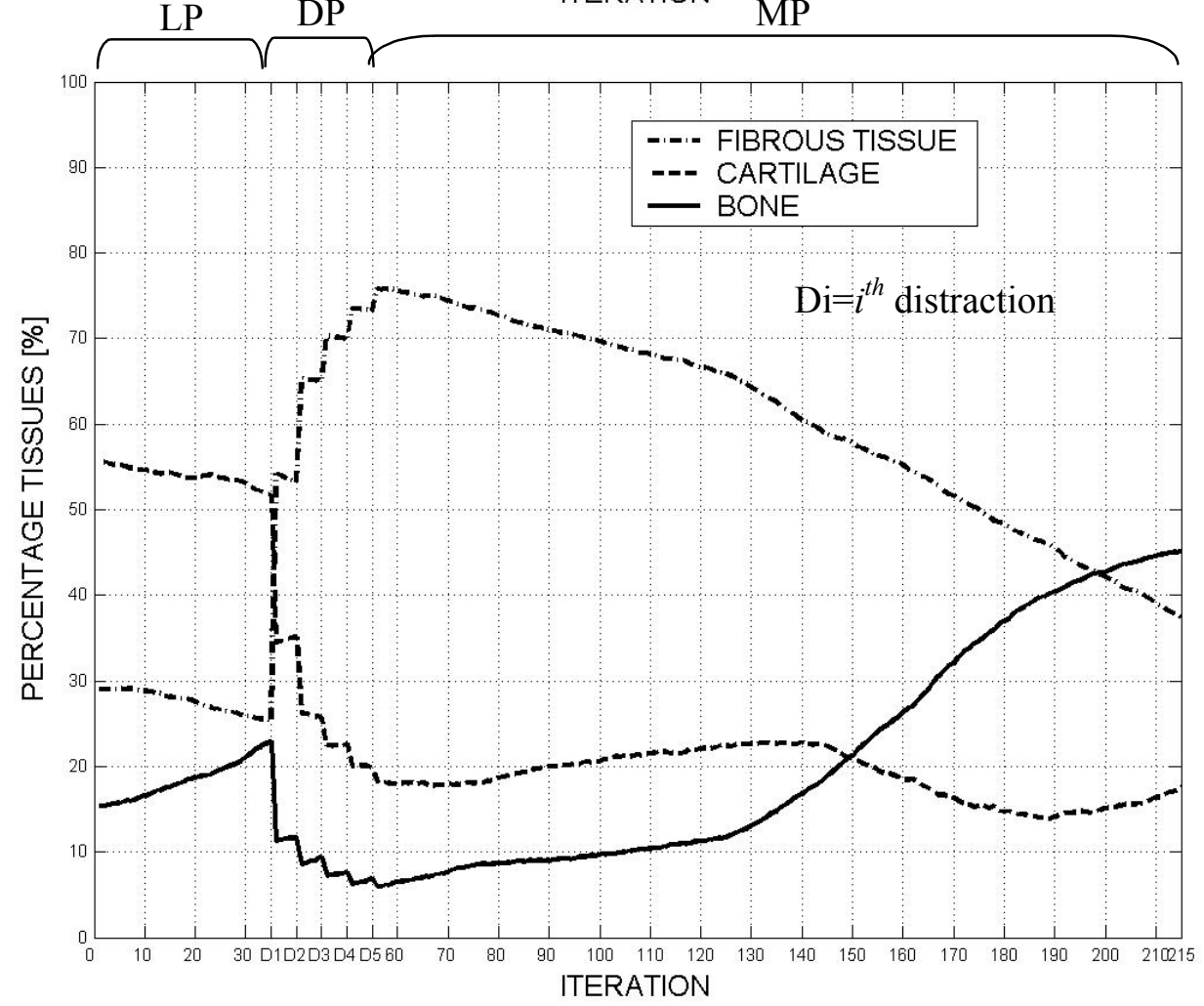

b)

Figure 8. Percentage values of the tissues composing the bone callus in the latency period (LP), distraction period (DP) and maturation period (MP), for both distraction rates: (a) $0.6 \mathrm{~mm} /$ day and (b) $1.2 \mathrm{~mm} /$ day. Every 5 iterations correspond to 1 day. Full mastication loads are applied. 



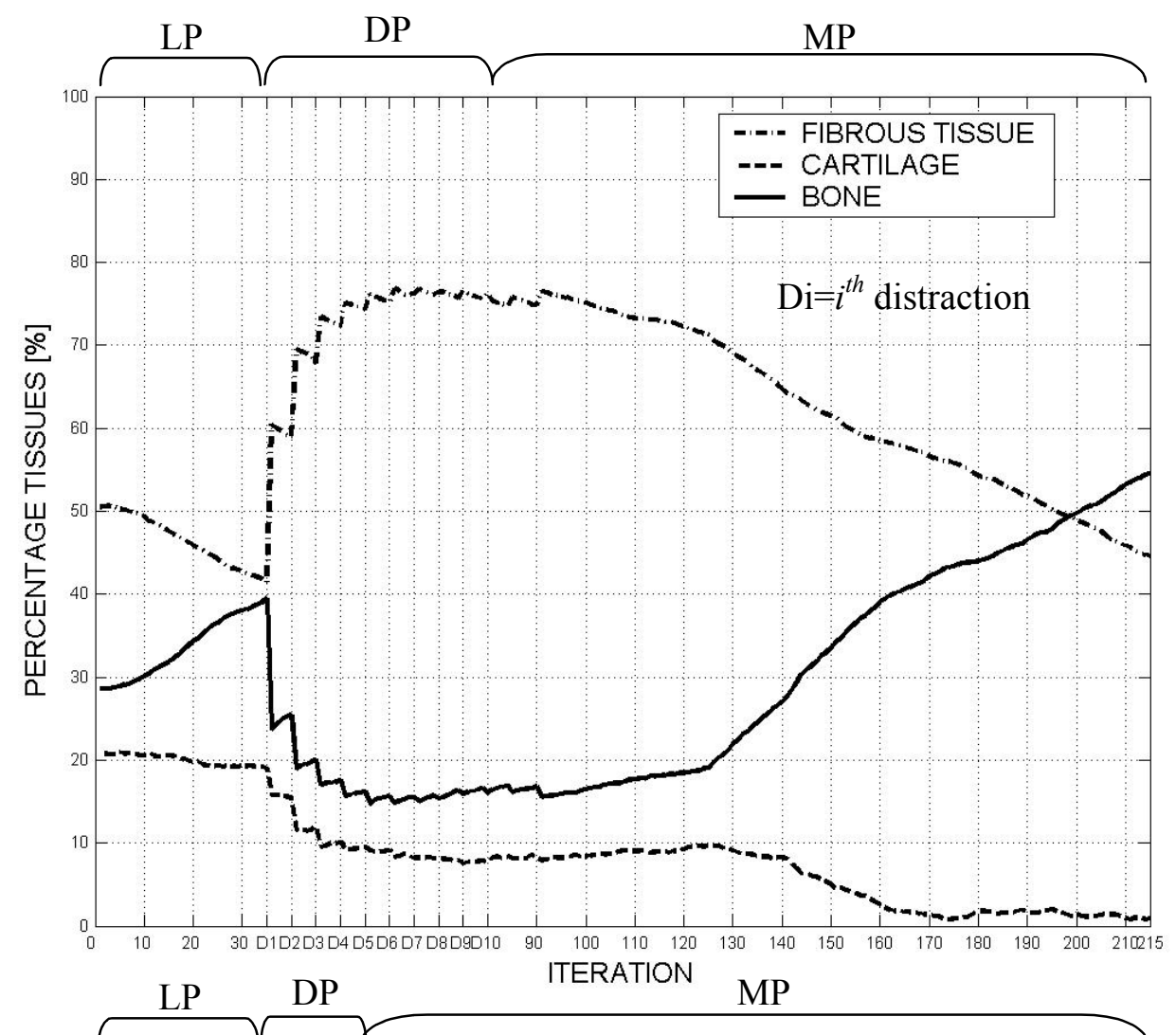

a)

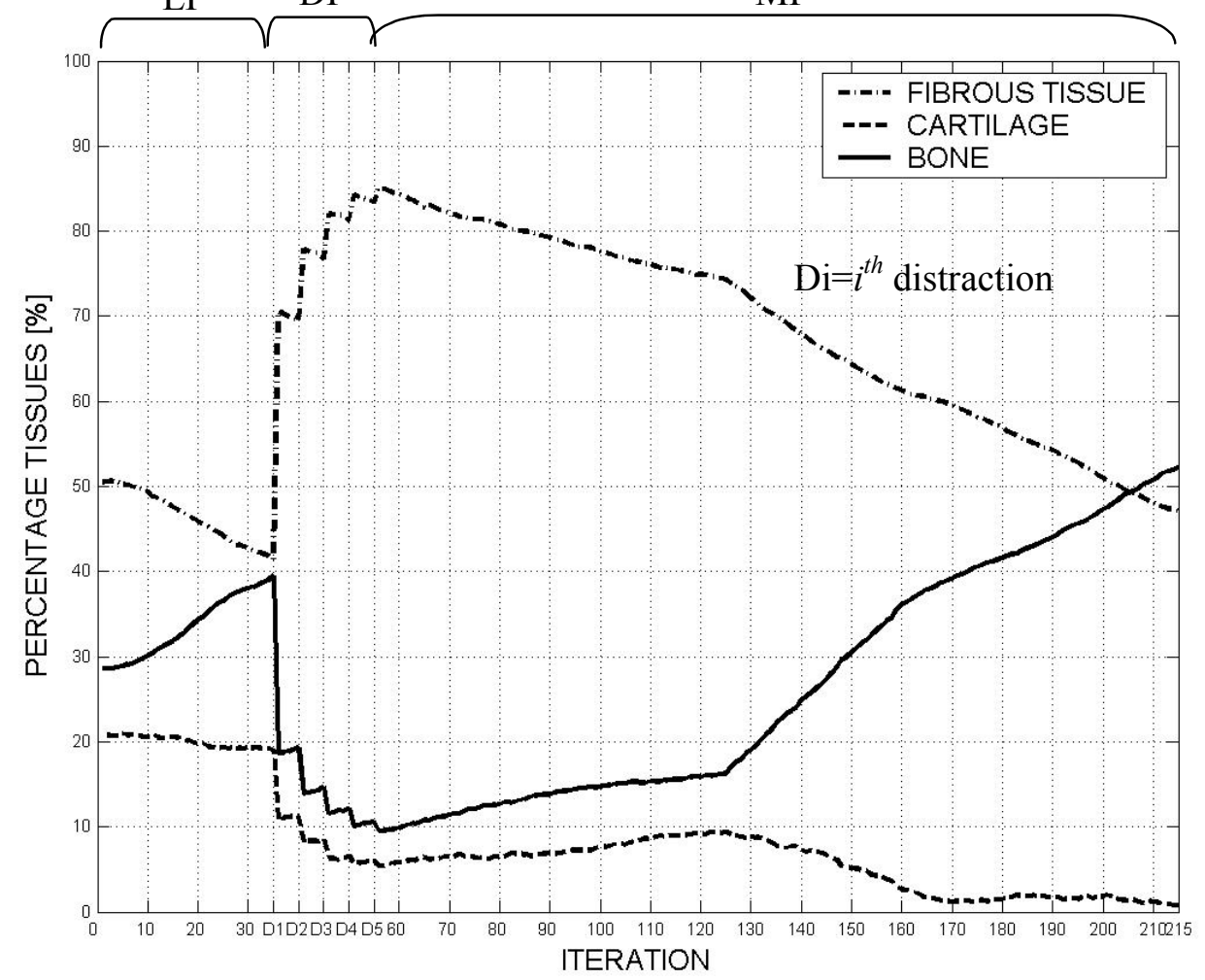

b)

Figure 9. Percentage values of the tissues composing the bone callus in the latency period (LP), distraction period (DP) and maturation period (MP), for both the two distraction rates: (a) $0.6 \mathrm{~mm} /$ day and (b) $1.2 \mathrm{~mm} /$ day. Every 5 iterations correspond to 1 day. Mastication loads reduced by $70 \%$ are applied. 


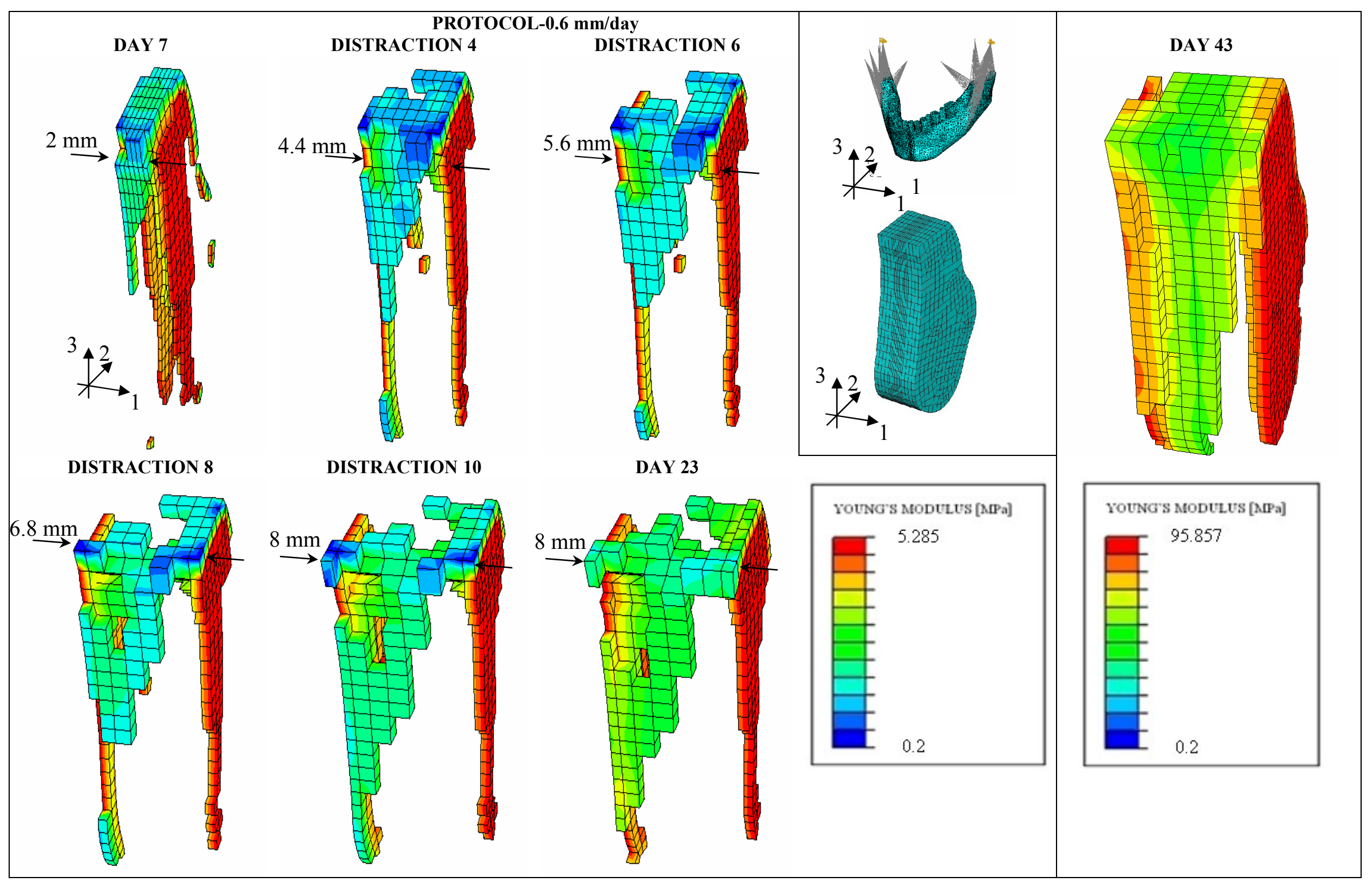

Figure 10. Bone regeneration process for a distraction rate of $1.2 \mathrm{~mm} /$ day. 


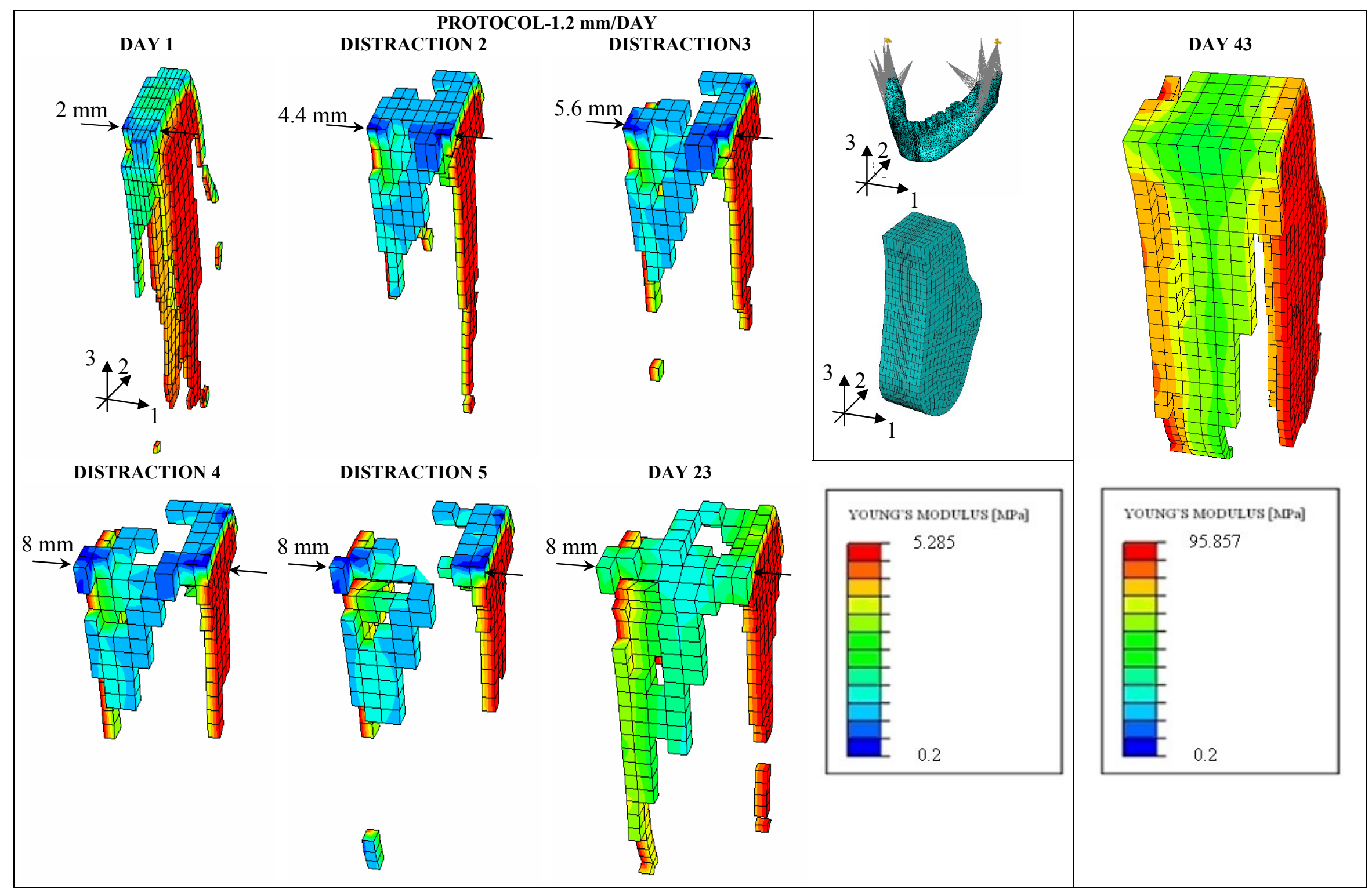

Figure 11. Bone regeneration process for a distraction rate of $1.2 \mathrm{~mm} /$ day. 


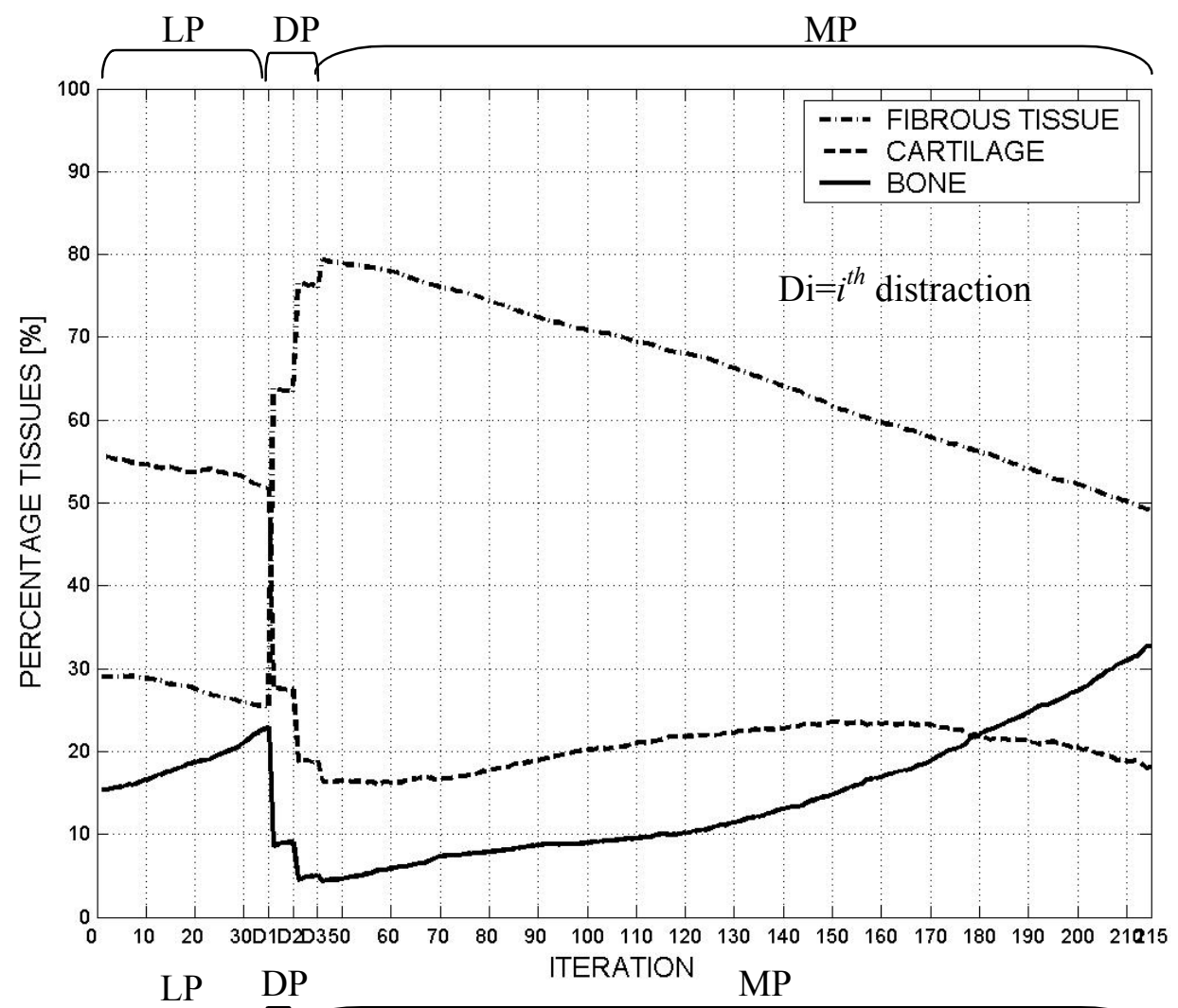

a)

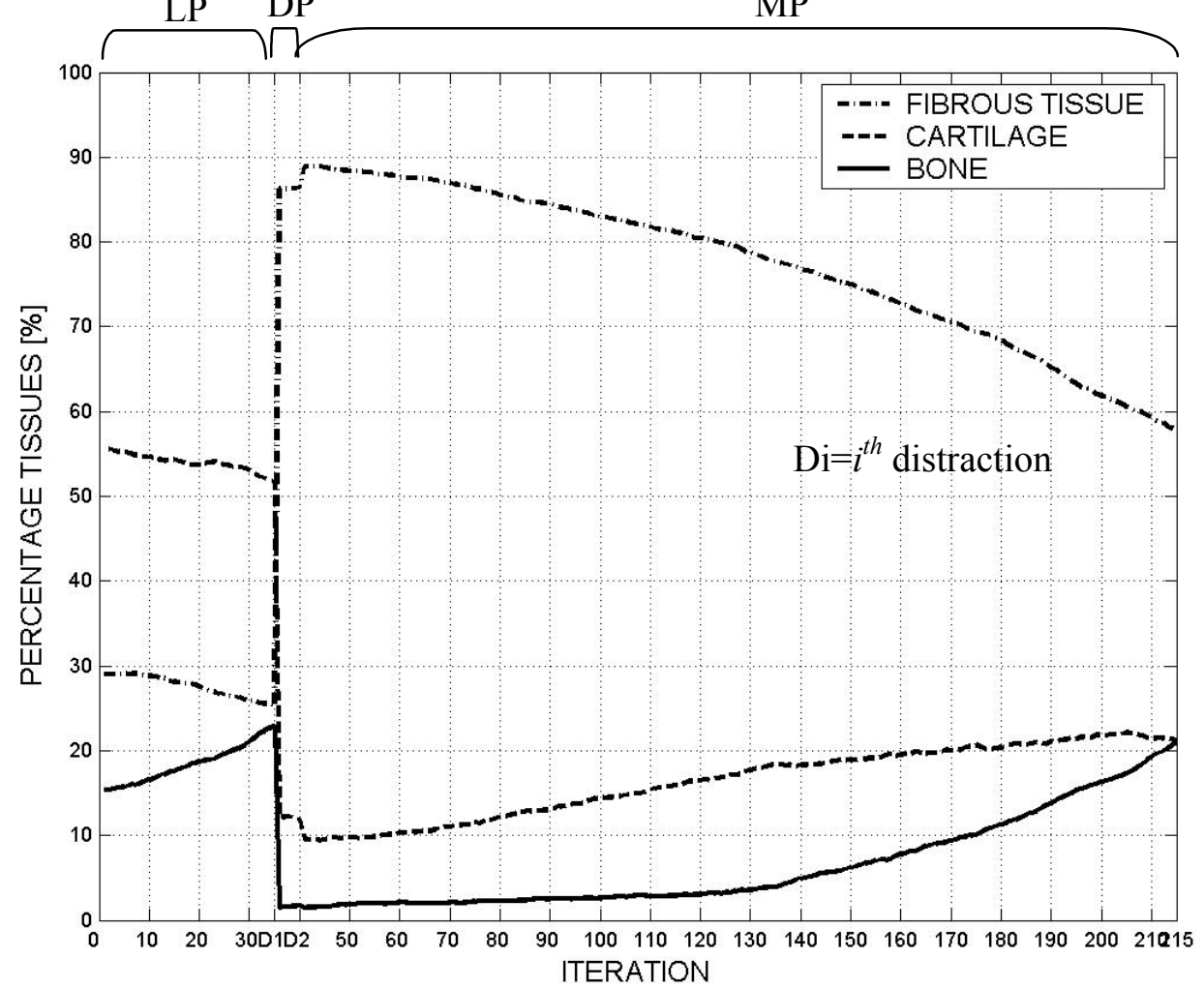

b)

Figure 12. Percentage values of the tissues composing the bone callus in the latency period (LP), distraction period (DP) and maturation period (MP), for the distraction rates of: (a) $2.0 \mathrm{~mm} /$ day and (b) $3.0 \mathrm{~mm} /$ day. Every 5 iterations correspond to 1 day. Full mastication loads are applied. 


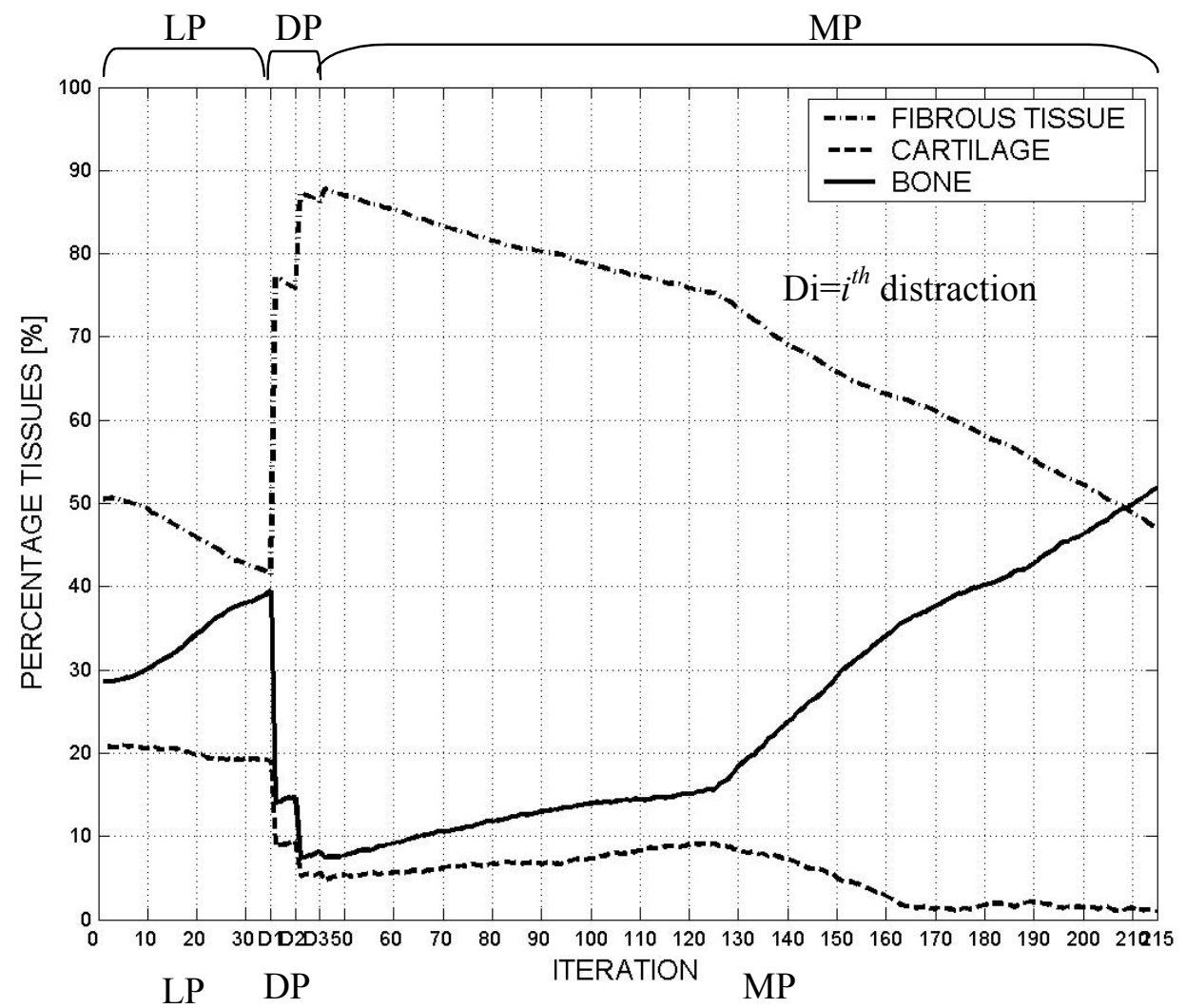

a)

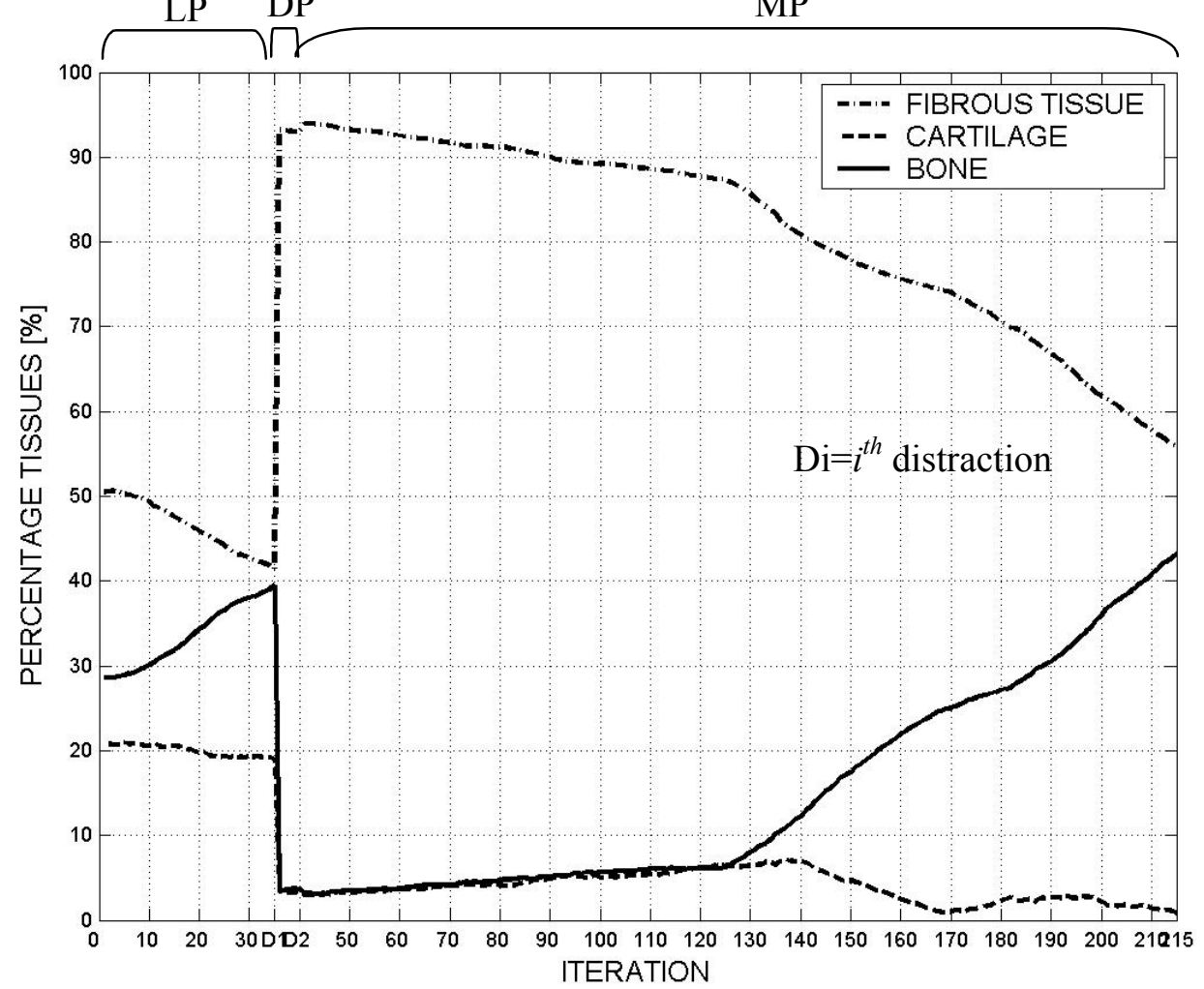

b)

Figure 13. Percentage values of the tissues composing the bone callus in the latency period (LP), distraction period (DP) and maturation period (MP), for the distraction rates of: (a) $2.0 \mathrm{~mm} /$ day and (b) $3.0 \mathrm{~mm} /$ day. Every 5 iterations correspond to 1 day. Mastication loads reduced by $70 \%$ are applied. 


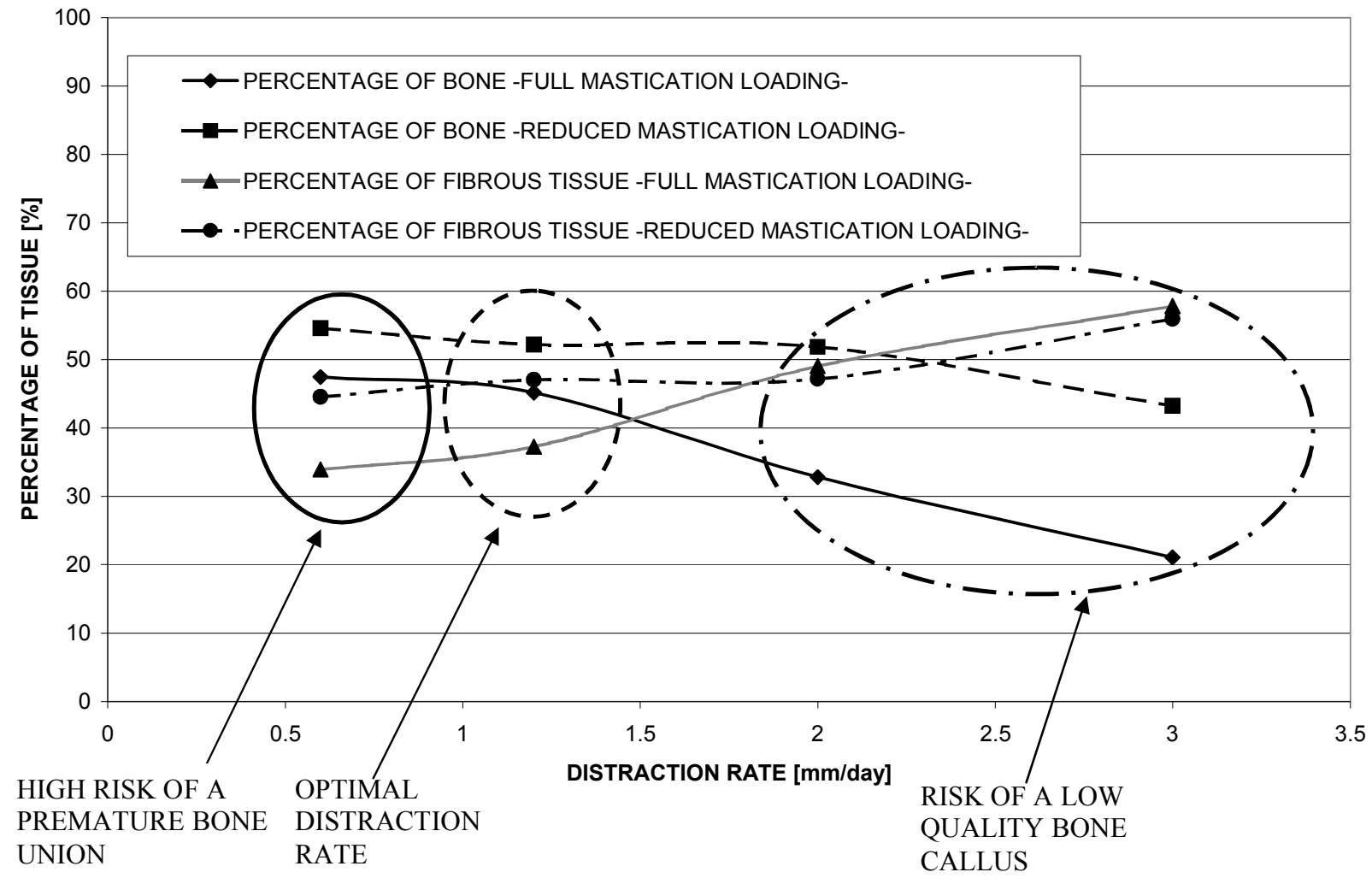

Figure 14. Amounts of bone and fibrous tissue predicted by the numerical model after 43 days since the osteotomy for both, the full and the reduced mastication loading. The higher amounts of bone bridging the callus for a distraction rate of $0.6 \mathrm{~mm} /$ day indicate a higher risk of a premature bone union. On the other hand, the significant percentage of fibrous tissue for distraction rates of 2 $\mathrm{mm} /$ day and $3 \mathrm{~mm} /$ day indicate the formation of a low quality bone callus. Therefore, the rate of 1.2 $\mathrm{mm}$ /day could be considered the optimal distraction rate as it is the best compromise between the risk of a premature bone union and the risk of a fibrous union. 

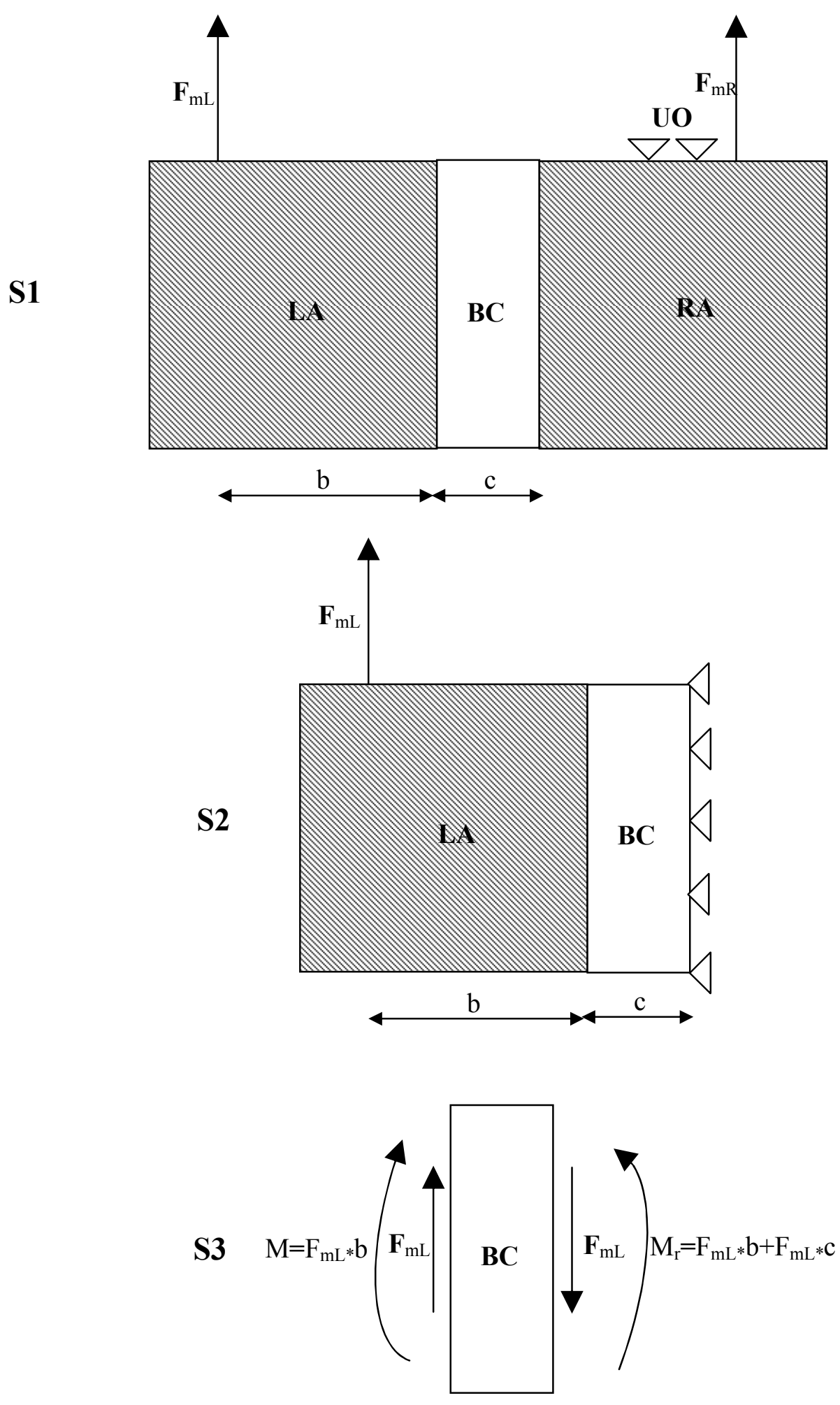

Figure A1. Evaluation of the reaction force acting on the left and on the right side of the bone callus. 